\title{
Dual Adhesive Unipolar Polysaccharides Synthesized by Overlapping Biosynthetic Pathways in Agrobacterium tumefaciens
}

\author{
Maureen C. Onyeziri ${ }^{1}$, Ramya Natarajan ${ }^{1}$, Gail G. Hardy ${ }^{1}$, Jing $X u^{1}$, Ian P. Reynolds ${ }^{1}$, \\ Jinwoo Kim ${ }^{1 a}$, Peter M. Merritt ${ }^{1}$, Thomas Danhorn ${ }^{1 b}$, Michael E. Hibbing ${ }^{1 \mathrm{c}}$, \\ Alexandra J. Weisberg ${ }^{2}$, Jeff H. Chang ${ }^{2}$ and Clay Fuqua ${ }^{1 *}$
}

Running Title: A. tumefaciens Unipolar Polysaccharide Adhesin

\author{
${ }^{1}$ Department of Biology \\ Indiana University \\ Bloomington, IN 47405 \\ ${ }^{2}$ Department of Botany and Plant Pathology \\ Oregon State University \\ Corvallis, OR 97331
}

*Address for correspondence: Clay Fuqua, Dept. Biol., 1001 E. $3^{\text {rd }}$ St., Biology Building 142, Indiana Univ., Bloomington, IN 47405-1847. Tel: 812-856-6005, FAX: 812-8556705, E-mail: cfuqua@indiana.edu

Current addresses: aDept. Plant Medicine, Gyeongsang National University, Jinju, Korea; bCtr. Genes Environ. Hlth., National Jewish Health, 1400 Jackson St., Denver CO 80206; ' Fimbrion Therapeutics, St. Louis MO 


\section{Summary}

Agrobacterium tumefaciens, is a member of the Alphaproteobacteria that pathogenizes plants, and associates with biotic and abiotic surfaces via a single cellular pole. $A$. tumefaciens produces the unipolar polysaccharide (UPP) at the site of surface contact. UPP production is normally surface-contact inducible, but elevated levels of the second messenger cyclic diguanylate monophosphate (cdGMP) bypass this requirement. Multiple lines of evidence suggest that the UPP has a central polysaccharide component. Using an A. tumefaciens derivative with elevated cdGMP and mutationally disabled for other dispensable polysaccharides, a series of related genetic screens have identified a large number of genes involved in UPP biosynthesis, most of which are Wzx-Wzy-type polysaccharide biosynthetic components. Extensive analyses of UPP production in these mutants have revealed that the UPP is comprised of two genetically, chemically and spatially discrete forms of polysaccharide, and that each requires a specific Wzy-type polymerase. Other important biosynthetic, processing and regulatory functions for UPP production are also revealed, some of which are common to both polysaccharides, and a subset of which are specific to each species. Many of the UPP genes identified are conserved among diverse rhizobia, whereas others are more lineage specific.

\section{Plain language summary}

Bacteria attach to a wide variety of surfaces including host tissues, via externalized structures described as adhesins. We define a large set of genes involved in synthesis of a complex unipolar adhesin comprised of two distinct polysaccharides, that is required for surface attachment by the plant-associated pathogen Agrobacterium tumefaciens. 


\section{Introduction}

Many pathogenic bacteria stably associate with the tissues of their hosts as an obligate component of infection. This physical association is usually mediated by adhesins elaborated from the bacterial surface, including pili, flagella, other externalized proteins and exopolysaccharides (Berne et al., 2018). Adhesins can also drive bacterial attachment to abiotic surfaces. On both abiotic surfaces and host tissues, adherent cells may assemble into multicellular biofilms, physically and chemically recalcitrant communities that can protect the colonizing bacterial population (Flemming et al., 2016). Biofilm formation is driven by a combination of cell-to-surface interactions, intercellular cohesion, and extrusion of exopolymeric materials to build an extracellular matrix.

We discovered a polysaccharide-based adhesin in Agrobacterium tumefaciens, a member of the Alphaproteobacteria (APB) and causative agent of crown gall disease on a wide variety of dicotyledonous plants (Gelvin, 2003). Crown gall is a neoplastic disease that results from the transfer of a large segment of DNA (T-DNA) from the bacteria into plant cells at the site of infection via the activity of a type IV secretion system (Li \& Christie, 2018). This interkingdom gene transfer process, both its regulation and the mechanism of transfer, has been the subject of intense study and T-DNA transfer has been extensively engineered for the generation of transgenic plants. There is, however limited, understanding of the initial colonization events that occur on the tissue surface, both for benign interactions and those that lead to the initiation of T-DNA transfer (Fuqua, 2008). Micrographs dating as early as the 1940s suggest that $A$. tumefaciens often 2009). Surfaces to which A. tumefaciens can attach include plant tissues and cells, other 
47 bacterial cells to form multicellular rosettes, and abiotic materials. We discovered that $A$. tumefaciens produces an adhesive structure at one of its poles that is predominantly comprised of polysaccharide, and hence we designated this the unipolar polysaccharide (UPP) (Tomlinson \& Fuqua, 2009). Fluorescently-tagged lectins including wheat germ

51 agglutinin (WGA) and Dolichos biflorus agglutinin (DBA) label the UPP as a small

52 fluorescent focus at the pole that is in contact with abiotic surfaces, plant tissues, and other bacterial cells (Fig. 1) (Xu et al., 2012, Xu et al., 2013). The UPP structure shares facile and functional similarity to the adhesive holdfast localized to the tip of the cellular stalk for the prosthecate APB Caulobacter crescentus (Poindexter, 1981). In fact, production of the UPP is coordinated with the biphasic life cycle of $A$. tumefaciens in a

57 similar fashion as the holdfast in C. crescentus, and is produced by mother cells, that are often adhered to surfaces, and will generate multiple progeny daughter cells via a polar budding mechanism (Brown et al., 2012). In both bacteria, production of the unipolar adhesin is stimulated by surface contact. In C. crescentus, this accelerates holdfast production to earlier in the cell cycle, but in $A$. tumefaciens surface contact is required for

62 cells to produce the UPP (Li et al., 2012). The smaller size and strict surface-contact dependence of UPP production led to it being overlooked for many years, relative to the

64 more microscopically conspicuous holdfast of C. crescentus. Several A. tumefaciens mutants have been characterized which exhibit a bypass of surface-contact dependence and elevated UPP production due to increased levels of the cytoplasmic second 67 messenger cyclic diguanylate monophosphate (cdGMP) (Feirer et al., 2017, Feirer et al., 
A cluster of six predicted polysaccharide biosynthetic genes (ATU_RS06125RS06100) was initially identified based on adhesion defects of a small number of mutants in $A$. tumefaciens (Fig. 2A) (Xu et al., 2012). These genes are homologous to six genes in a syntenic cluster required for synthesis of a glucomannan involved in recognition of host legumes during formation of symbiotic nodules in the related symbiotic nitrogenfixing APB Rhizobium leguminosarum bv. viciae (Williams et al., 2008). Deletion of the entire six-gene cluster in $A$. tumefaciens led to complete loss of biofilm formation on abiotic surfaces and abolished lectin labeling of the UPP (Xu et al., 2012). In-frame

77 deletion of a single gene in this cluster (ATU_RS06105) encoding a polyisoprenylphosphate hexose-1-phosphate transferase (PHPT) homologous to the HfsE glycosyltransferase from C. crescentus required for holdfast synthesis (Toh et al., 2008), also abolished surface attachment and visible UPP production. In addition to this PHPT protein, the other five genes in this cluster encode homologs to polysaccharide biosynthesis genes (Table S1), and we have tentatively designated this gene cluster as uppABCDEF (Thompson et al., 2018). In addition to the PHPT protein UppE, several of

84 these genes encode components of a Wzx-Wzy-type polysaccharide pathway (Cuthbertson et al., 2009). Using the general polysaccharide biosynthetic nomenclature,

86 UppE encodes a WbaP initiating glycosyltransferase, UppB (ATU_RS06120) encodes a

87 predicted Wzb-type periplasmic co-polymerase (PCP), and UppC (ATU_RS06115) encodes a putative Wza-type outer membrane polysaccharide secretin (OPX). The other three genes are not restricted to Wzx-Wzy systems, but are still predicted polysaccharide biosynthesis genes (Table S1); UppA (ATU_RS06125) encodes a putative

91 polysaccharide acetyltransferase with similarity to BcsL involved in bacterial cellulose 
92 synthesis, UppD (ATU_RS06110) encodes a Type 4 glycosyltransferase (GT4), and

93 UppF (ATU_RS06100) is similar to WaaL O-antigen ligases that often transfer

94 polysaccharides to the core of lipopolysaccharide (LPS), in formation of the O-antigen or

95 LPS-conjugated polysaccharides (Romling \& Galperin, 2015, Ruan et al., 2018).

The upp gene cluster is completely or partially conserved among diverse members

97 of the Rhizobiales, and mutations in several of these homologs have been shown to impact production of a unipolar polysaccharide and rosette formation in Rhodopseudomonas palustris (Fritts et al., 2017). Thus, in at least three members of the Rhizobiales, homologs of the $A$. tumefaciens uppA-F genes are required for synthesis of polar polysaccharides, and it seems likely that this function is conserved in these bacteria. However, notably absent from these gene clusters are homologs of the Wzx-type polysaccharide flippase enzymes and the Wzy-type polysaccharide polymerases, two of the defining components of these pathways (Cuthbertson et al., 2009). In this study, we use several distinct forward genetic approaches along with targeted mutational analysis to expand and deepen our prior analyses on A. tumefaciens UPP biosynthesis, identifying over 16 additional genes in 6 genomic clusters that are required for UPP production and attachment to surfaces. We combine this genetic analysis with microscopy and functional assays to reveal that there are at least two distinct polysaccharides that both contribute to the A. tumefaciens UPP, and that the biosynthetic pathways are genetically separable,

111 but also overlapping and co-regulated. 


\section{Results}

\section{Mutations in the uppABCDEF gene cluster disrupt attachment and UPP production}

117 While performing a biofilm deficiency screen, we initially isolated a Mariner (Himar1)

118 transposon mutant of $A$. tumefaciens C58 that was completely deficient for biofilm

119 formation on PVC coverslips relative to wild type (Xu et al., 2012). The transposon in this

120 mutant was immediately upstream of the gene we now designate as uppE (Fig. 2A,

121 unfilled transposon marker). Creation of a mutant with an in-frame deletion of uppE

122 (ATU_RS06105) resulted in an equivalent loss of biofilm formation and WGA labeling as

123 in the transposon mutant (Figs. 3, 4). To test the other genes in the uppABCDEF cluster

124 (ATU_RS06125-RS06100), we created in-frame deletions of each gene individually and

125 observed significant decreases in biofilm formation on PVC coverslips (Fig. 3, Table S1).

126 The uppC and uppE deletions exhibited the most profound defects, but the uppA, uppB,

$127 u p p D$ and $u p p F$ deletions also were substantially decreased biofilm formation, although

128 still detectable. Short term attachment assays with cells incubated on PVC coverslips

129 revealed weak attachment in all mutants and loss of labeling with Alexafluor594-tagged

WGA (af-WGA) for all of the mutants (Fig. 4, Table S1). Attachment and biofilm formation

132 plasmid-borne copies of these genes, with the exception of the uppC mutant, which was

133 only partially complemented with the $P_{\text {lac }}-$ uppC plasmid (Fig. 3). We realized that the

134 uppC deletion also impacted the overlapping downstream uppD coding sequence, and

135 provision of a plasmid expressing both $u p p C$ and $u p p D$ fully reversed the $\triangle u p p C$ mutant

136 phenotype. As described above, the six upp genes are all homologs of polysaccharide

137 biosynthetic functions (Table S1). However, it was clear that based on their predicted 
138 functions in a Wzx-Wzy-type pathway, they would not be sufficient and that there must be additional genes required for UPP synthesis. Most notably, homologs of both the Wzx flippase and the Wzy polymerase are not found in this gene cluster nor in proximal genes.

\section{A facile genetic screen for UPP biosynthetic genes}

143 In prior studies, we had identified a set of mutants in four different loci (visR ATU_RS02585, claR ATU_RS08010, pruA ATU_RS05580, and dcpA ATU_RS16190),

145 that manifested elevated production of the UPP coincident with elevated cellular cdGMP levels (Feirer et al., 2017, Feirer et al., 2015, Xu et al., 2013). The screen was based on the polysaccharide-binding, azo-dye Congo red (CR, which can also bind to $\beta$-amyloid proteins), and in all cases elevated CR pigmentation correlated with increased UPP production and hyper-adherence to surfaces. Wild type A. tumefaciens forms very pale orange colonies when cultured on agar plates of a standard minimal medium (ATGN) cellulose results in red pigmentation of bacterial colonies grown on ATGN-CR, which we

155 UPP production. In the current study, we utilized this same CR-based screen, but performed it with the four different ECR mutants, each with in-frame deletions in the

157 relevant regulatory genes ( $\Delta v i s R, \Delta c l a R, \Delta p r u A$, and $\Delta d c p A)$. These strains were also 
generally designate these strains as ECR (CDGS-) derivatives (the specific deleted regulator resulting in the ECR phenotype is indicated as required).

Mariner (Himar-1) transposon mutant libraries of each strain were screened for colonies with a notable decrease in CR pigmentation (the DCR phenotype), reasoning that we would likely isolate mutations in UPP biosynthetic functions, as well as positive regulatory elements required for the ECR phenotype. Overall, we screened close to 50,000 colonies of these derivatives for the DCR phenotype. Once confirmed as DCR mutants, the transposon insertion site junctions were amplified and sequenced. From this initial screen 140 independent mutants were identified in 19 discrete annotated genes (Fig. 2, Table S2), most predicted to be involved in polysaccharide biosynthesis or clustered with such genes (other DCR mutants were in known or predicted regulatory functions, see Xu et al., 2013). All but one of the 19 disrupted loci were identified multiple times, and mutations in all but two genes were found in more than one of the mutants used in the screen, with 9 genes identified in at least three different mutant backgrounds (Table S2). Subsequent analyses revealed that most of the genes disrupted by Mariner insertions in the DCR mutants, when deleted and retested in new genetic backgrounds, resulted in decreased or absent UPP production and decreased biofilm formation (Fig. S1, Table S1). Of the genes identified, four were in the previously characterized uppA-F cluster (number of mutants); uppB (2), uppC (14), uppD (6), and uppE (16) for a total of $38(27 \%)$ of the independent mutants (Fig. 2A). No DCR mutations were identified in uppA and $u p p F$. The identification of four of the genes in this cluster however, validated the ability of our DCR screen to detect defects in UPP biosynthesis. 


\section{Identification of two Wzx flippase homologs that impact UPP production}

184

185

186

187

188

189

190

191

192

193

194

195

196

197

198

199

200

201

202

203

204

205

One of the required Wzx-Wzy pathway functions that had not been identified previously was a flippase (Wzx) homolog. The DCR screen identified two different Wzx-type genes (Fig. 2B, 2C; Tables S1, S2). In all four mutant backgrounds used in the screen, 21 independent mutations were obtained in a Wzx-type flippase homolog, ATU_RS02360, that we now designate uppX. This gene encodes a 426 aa protein, with $10-12$ predicted transmembrane helices, as is consistent with many flippase homologs (Hong et al., 2018). In-frame deletion of uppX in the wild type C58 strain resulted in a dramatic loss of biofilm formation (Fig. 5A) and attachment, as well as UPP production as judged by WGA and DBA labeling (Fig. 5B). These phenotypes were fully complemented by expression of a plasmid-borne copy of uppX. Divergently oriented from uppX is ATU_RS02370 (Fig. 2B), encoding a Wzy-type protein predicted to function as a polysaccharide polymerase, but no DCR transposon mutants were obtained in this gene. Interestingly, DCR mutations in a second flippase homologue were also identified, ATU_RS16320, now designated uppV (Fig. 2C, Table S1). UppV is a 477 aa Wzx-type protein, also with 12 predicted transmembrane domains. Only two mutations in upp $V$ were isolated, but one each in the $\triangle p r u A$ and $\triangle d c p A$ mutants (Table S2). Deletion of uppV in wild type C58 significantly decreased but did not abolish biofilm formation relative to wild type (Fig. 5A), although weak attachment and no substantial WGA lectin binding was observed (Fig. 5B).

The uppV coding sequence terminates $8 \mathrm{bp}$ upstream of another reading frame, ATU_RS16325, that we have designated uppQ (Fig. 2C). Fifteen independent DCR mutants were isolated with insertions in $u p p Q$, which is oriented convergently to an adjacent unidentified reading frame (ATU_RS16330), strongly suggesting that uppQ itself 
206 is required for UPP production. UppQ is homologous to acetyltransferases of the GNAT

207 family of enzymes (Vetting et al., 2005), and paralogous to UppA (ATU_RS06125) (Table

208 S1). Deletion of $u p p Q$ in the wild type results in loss of WGA lectin binding and has a 209 strong biofilm defect (Fig. S1, Table S1) suggesting it plays a crucial role in UPP 210 biosynthesis.

A gene cluster of multiple polysaccharide biosynthetic genes with roles in UPP biosynthesis and biofilm formation

Strikingly, 47 of the DCR mutants (33.6\%) had transposon insertions in a single gene cluster ATU_RS11550-RS11590, with mutations represented in all four screening backgrounds, and multiple independent mutations identified for all of these genes (Fig. 2D). Seven of these annotated genes have predicted polysaccharide-related functions, 218 and the others genes encode hypothetical functions. Nine out of ten genes in this 219 contiguous cluster were identified in the DCR screen, with the exception of ATU_RS11580, a hypothetical gene (Fig. 2D). The genes are organized into at least 4 different predicted transcription units. Multiple lines of evidence for most of these genes

222 indicate roles in UPP biosynthesis and hence we have designated them uppG through 223 uppO (Fig. 2D, Fig. S1, Table S1). Four of these genes are predicted to encode 224 cytoplasmic glycosyl transferases (GTs) uppG is in the Carbohydrate Active Enzymes 225 (CAZy) group GT4, uppl and uppJ in CAZy group GT2, and uppL (CAZy group 26) 226 (Lombard et al., 2014). The uppH gene encodes a predicted periplasmic Class 10 227 glycoside hydrolase, uppM encodes a periplasmic co-polymerase (PCP-2b), and uppO encodes a phosphomannomutase. Two of the genes interrupted among the DCR 
229 transposon mutants, uppK and uppN are predicted to encode proteins of unknown

230 function, and in fact the short 59 amino acid coding sequence we designate as uppN is

231 not annotated as a gene in the current $A$. tumefaciens genome annotation (although it

232 was designated as Atu2378 in an earlier genome annotation).

234 the wild type C58 background, and tested for biofilm formation defects. Profound defects were observed for $\Delta u p p G, \Delta u p p l, \Delta u p p J, \Delta u p p L, \Delta u p p M$, and $\Delta u p p N$ (Fig. S1 and Table

236 S1). Ectopic expression of the disrupted gene complemented the deletion mutants for uppG, uppl, uppJ, and uppL (Table S1, Fig. S2A). In frame deletion of uppH did not have an impact on attachment, but the gene overlaps by 4 bp with the upp $G$ coding sequence and multiple lines of evidence suggest that the uppH transposon mutations are polar on uppG. However, subsequent analysis revealed an important activity of UppH relevant to the UPP (described below). dramatic loss of biofilm formation, but complementation did not effectively restore this 244 phenotype (Fig. S1A, S2A). Initially, we thought this might be due to polarity on the 245 phosphomannomutase uppO, although it is $155 \mathrm{bp}$ downstream of the uppN gene (Fig. 246 2D). However, in frame deletion of uppO did not result in a biofilm defect in a wild type 247 background and seemed to result in greater adherence (Fig. S1A), despite the isolation 248 of four DCR transposon mutants with insertions in this gene. Thus, any unexpected 249 polarity on uppO apparently does not explain the $\Delta u p p N$ phenotype, and its weak 250 complementation. Similar to uppO, in-frame deletion of the hypothetical gene uppK did 251 not impact biofilm formation, in the wild type (Fig. S1A). We hypothesized that the 
252 difference might be due to the elevated cdGMP in the mutants used for DCR screening,

253 whereas the uppK deletion was in the wild type. However, introduction of the $\Delta p r u A$

254 deletion that dramatically increases cdGMP and in which we isolated all 4 uppK transposon mutants, increased adherence in the wild type, and this was not diminished by the $\Delta$ uppK mutation (Fig. S2b).

\section{Mutations in uppM and uppB have additive defects.}

259 The UppM protein is homologous to Type 2b periplasmic co-polymerases (PCP-2b), and 260 is paralogous to UppB. In-frame deletion of uppM in the wild type resulted in a significant, 261 yet incomplete loss of biofilm formation (Fig. S1A, Table S1). Given the similarity of UppM

262 and UppB, we speculated that a functional uppB gene might partially mask the full 263 attachment defect, as the $\triangle u p p B$ mutant also exhibits an incomplete loss of biofilm 264 formation (Fig. 3). A mutant with both uppB and uppM deleted shows a complete loss of 265 biofilm formation (Fig. S2C), lower than either mutation alone, consistent with their similar 266 roles in UPP biosynthesis.

\section{The UppG glycosyl transferase catalytic site is required for full UPP synthesis.}

269 Careful examination of the $\triangle u p p G$ mutant revealed that it does in fact bind to the WGA 270 lectin, but that the signal is significantly weaker than the wild type (Fig. S3A, S3B). We

271 recreated this deletion in the $\triangle$ pruA CDGS- screening strain, and found it to be fully 272 complemented by a plasmid-borne copy of the gene as evaluated by CR colony staining 273 (Fig. S3C). GT4-Class glycosyltransferases similar to UppG have a conserved DXD 274 catalytic motif (Breton et al., 2006). Mutation of the predicted DXD active site motif (pos. 
275 142-4) at the first $D$ residue (DXD>AXD) abolished complementation (Fig. S3C), 276 confirming a requirement for its GT activity in this and related phenotypes.

A predicted outer membrane protein required for UPP synthesis

279 Nine independent DCR mutants had transposon insertions within or immediately 280 upstream of the ATU_RS1765 gene and we have designated this gene as uppP (Fig. 2E).

281 One of the nine transposon insertion mutants mapped to the short annotated 106 aa 282 upstream hypothetical coding sequence ATU_RS1760 which terminates 6 bp upstream 283 of the predicted uppP start codon. This single transposon insertion is likely polar on uppP. UppP is 497 aa in length, has an N-terminal secretion signal and encodes an outer membrane $\beta$-barrel-type II porin protein (Table S1). UppP is much larger than the predicted polysaccharide secretin UppC (190 aa), does not match well with Wza

287 homologues, and unlike UppC, lacks a lipidation motif. The uppP gene is convergently oriented to a GalU homologue (ATU_RS17570), predicted to encode a UTP-glucose-1phosphate uridylyltransferase, that could synthesize a UDP-glucose precursor, but no DCR mutants were isolated that had insertions in this gene (although it is implicated by

292 complete loss of biofilm formation and was fully complemented by plasmid-borne 


\section{Mutations in the exoC gene result in the DCR phenotype}

Eight independent DCR mutants were found to have transposon insertions within

ATU_RS19035 (Fig. 2F), encoding a gene previously designated as exoC (Kamoun et

al., 1989). The exoC gene product encodes a predicted phosphoglucomutase that would

sugar nucleotide substrates for polysaccharide biosynthesis. Mutants in exoC have been biosynthesis and utilization (Fig. 2F). However, none of the other genes in this cluster, other than exoC, were isolated in the DCR screen.

\section{Apparent redundancy for Wzy-type polymerase function(s)}

316 The DCR screen described above revealed a large number of additional genes required

317 for UPP biosynthesis. Despite the wide range of polysaccharide-related functions 318 identified, it was surprising that no DCR mutants were isolated with mutations in Wzytype polymerase homologs, despite the divergent orientation from uppX of a gene 
321 Wzy polymerase activity required for a Wzx-Wzy-type pathway, might be fulfilled by

322 functionally redundant proteins. Examination of the C58 genome revealed a Wzy-type

323 protein paralogous to ATU_RS02370, ATU_RS11495 to be the closest match, (37\%

324 identity, 57\% similar). As described below, we have designated these genes as uppY

325 (ATU_RS02370) and uppW(ATU_RS11495) (Fig. 6A). Single, in-frame deletions of uppY

326 and uppW did not result in any discernable change in CR colony pigmentation nor for

327 adhesion based on in vitro biofilm assays (Fig. 6B, 6C). However, combination of the

328 uppY and uppW deletions resulted in the DCR phenotype in the $\triangle p r u A$ CDGS- mutant

329 (Fig. 6B) and abolishment of biofilm formation in an otherwise wild-type strain (Fig. 6C).

330 Expression of plasmid-borne copies of either gene complemented the $\Delta u p p Y \Delta u p p W$

331 mutant for adhesion. UppY and UppW are both Wzy-type RfaA homologs with 10

332 predicted transmembrane domains, that could function as polysaccharide polymerases

333 in the periplasm. Our observations suggested that either UppY or UppW can compensate

334 for the absence of its paralog, for CR interactions and for adhesion in our in vitro assays.

335 Initially, the explanation for this functional redundancy was unclear, but we now recognize

336 that each protein plays a specific role in forming the UPP adhesin.

The UPP adhesin is composed of two chemically and genetically distinct

polysaccharides

340 The large number of putative UPP genes we identified from the DCR screen was striking

341 given an apparent duplication of function for many of the requisite steps involved in Wzx-

342 Wzy-type polysaccharide synthesis (Fig. 2, Table S1). Previously, A. tumefaciens UPP

343 synthesis was examined using multiple lectins with different oligosaccharide specificities 
344 (Xu et al., 2012). In addition to GIcNAc residues recognized by WGA, the lectin from the 345 legume Dolichos biflorus (DBA) has specificity for $N$-acetylgalactosamine residues

346 (GalNAc) and effectively labels the $A$. tumefaciens UPP. We performed dual labeling experiments with af-WGA and fl-DBA of $A$. tumefaciens ( $\triangle$ pruA CDGS-) cells adhered to coverslips. Both lectins labeled the poles for a large proportion of adhered cells (Fig. 7). The pattern of labeling was striking with the fl-DBA fluorescence forming a tight focus at the point of contact, and the af-WGA labeling more diffusely bound in a second ring 351 around the DBA-labeled sector. This suggested that there were two discrete populations 352 of polysaccharide at the pole, one identifiable using the GICNAc-specific WGA and a 353 second labeled with the GalNAc-specific DBA. We tentatively designated these two 354 polysaccharide species as UPP $\mathrm{GlcN}$ and $\mathrm{UPP}_{\mathrm{GalN}}$, respectively. The basis for the clear 355 spatial segregation of the lectin labeling pattern was initially unknown. corresponding polysaccharide (Fig. 8). In short-term coverslip binding assays probed simultaneously with both lectins, the $\Delta u p p Y$ mutation caused loss of all fl-DBA labeling, but did not affect that of af-WGA, whereas the $\Delta u p p W$ mutation caused loss of the afWGA labeling but retained that of fl-DBA. The double mutant, which abolished elevated 363 CR binding and biofilm formation, was unable to bind either lectin. This suggested that 364 production of the DBA-labeled UPPGalN requires UppY, whereas elaboration of the WGA365 labeled UPP ${ }_{G I c N}$ requires the function of UppW. 
UPP polysaccharide production was examined using transmission electron microscopy (TEM) and lectins conjugated with colloidal gold beads. The A. tumefaciens $\triangle$ pruA CDGS- strain was used for these experiments to eliminate additional polysaccharides that can obscure visualization of the UPP and because the surfacecontact dependence of the wild type strain makes TEM of adhered cells challenging. The appropriate cultures were grown and probed with each lectin preparation individually, and then incubated with the general TEM reagent uranyl acetate. In the strain with functional copies of both uppY and uppW, the UPP could be observed as fibrous material at a single

374 pole of the cell, that was absent in the $\Delta u p p Y \Delta u p p W$ mutant (Fig. 9). The gold-labeled 375 WGA (20 $\mathrm{nm})$ bound this fibrous material quite effectively and no binding was observed 376 for the $\Delta u p p Y \Delta u p p W$ mutant. Fibrous polar material was visible for the single $\Delta u p p Y$ and $\Delta u p p W$ mutants, but the labeled WGA only bound efficiently to the fibers observed in the $\Delta u p p Y$ mutant, and not those on the $\Delta u p p W$ mutant (Fig. 9A). Initial experiments with the gold-labeled DBA lectin, revealed it to bind very inconsistently to the UPP (data not shown). We found that the lectin from peanut (PNA) that also binds to polysaccharides with GalNAc residues, gave more consistent results (Fig. 9B). The PNA lectin bound to

382 the fibrous material for the cells that were wild type for both uppY and uppW, and the $\triangle u p p W$ mutant, but no binding to the $\triangle u p p Y$ mutant or the double mutant. Although this pattern was observed consistently, it was clear that this lectin binds much less efficiently in this experiment to the UPP, than does WGA. The basis for this weaker binding remains to be determined. 


\section{UppH encodes a glycoside hydrolase capable of destabilizing the UPP}

390 The uppH gene (ATU_RS1155) was found to be largely dispensable for adhesion and UPP production (Fig. S2A, Table S1). However, it was predicted to be a periplasmic Class 10 glycoside hydrolase, and its position within the uppG-O cluster implicated it in UPP production. Periplasmic glycoside hydrolases are often encoded within polysaccharide biosynthetic gene clusters, and are thought to hydrolyze glycosidic bonds within the associated polysaccharide as it transits this cellular compartment (Oglesby et al., 2008).

Recently it was reported that exogenous addition of the purified PelAh and PsIGh periplasmic glycoside hydrolases from Pseudomonas aeruginosa enzymes can disrupt Pel and Psl-dependent biofilms through cleavage of these polysaccharides (Baker et al.,

2016). A derivative of $\mathrm{UppH}$ with its $\mathrm{N}$-terminal secretion signal replaced by a hexahistidinyl tag (His6) was purified. His6-UppH was added in standard culture media (1 $\mu \mathrm{M}$ final concentration) to coverslips on which A. tumefaciens ( $\triangle$ pruA CDGS-) had been allowed to adhere for $2 \mathrm{~h}$, and incubated for an additional $1 \mathrm{~h}$, followed by dual lectin labeling with af-WGA and fl-DBA. In the untreated samples, many cells were polarly attached and visibly labeled with one or both lectins (Fig. 10). Addition of the UppH enzyme to these attached populations did not dislocate the cells, but removed visible

406 lectin-labeled polysaccharide. In parallel, we generated and purified a site-specific UppH 407 mutant in which two predicted catalytic glutamate codons were mutated to glutamine 408 codons to create $\mathrm{UppH}^{* *}$ (E152Q E266Q). Similar addition of exogenous, purified UppH ${ }^{* *}$ 409 at $1 \mu \mathrm{M}$ had no impact on lectin labeling (Fig. 10). We also examined UppH activity using 410 TEM, and found that pre-incubation of $A$. tumefaciens $\triangle p r u A$ CDGS- strain with the same 
412 in poles with no visible fibers, whereas incubation with the $\mathrm{UppH}^{* *}$ mutant did not affect

413 these fibers. Similar to studies using the $P$. aeruginosa glycoside hydrolases (Baker et

414 al., 2016), addition of increasing concentrations of purified His6-UppH added at the

415 beginning of cultivation inhibited $A$. tumefaciens biofilm formation (Fig. S5), whereas the

416 catalytic site mutant had no effect (data not shown).

A second genetic screen to distinguish between UppY-and UppW-dependent UPP biosynthetic pathways

Our findings suggest that there are two distinguishable polysaccharides that comprise the UPP, UPPGaIN and UPPGIcN, and that each polysaccharide species requires a specific Wzy-type protein, UppY and UppW, respectively. The individual $\Delta u p p Y$ and $\Delta u p p W$ deletion mutants in uppC (Wza, OPX, outer membrane secretin), uppX (Wzx, flippase), uppE (WbaP, PHPT initiating glycosyltransferase) and uppQ (GNAT acetyltransferase), functions that are required for production of both polysaccharides, whereas others, such as UppY and UppW, are specific to each polysaccharide. To identify UPP-related

431 functions specific to each polysaccharide and those that play a role for both, a variation

432 of the initial DCR was developed. Neither the individual uppY or the uppW mutant has a 433 DCR phenotype in the $\triangle$ pruA CDGS- background. We reasoned that additional loss of 434 the other UPP polysaccharide in these single mutants would cause a significant DCR 
435 colony phenotype as observed for the $\Delta u p p Y \Delta u p p W$ mutant (Fig. S6). Two strains were transposon mutagenized in parallel: the A. tumefaciens $\triangle p r u A C^{-} G^{-}$strain deleted for

437 either the uppY gene or the uppW gene. We then screened these transposon mutant 438 libraries for DCR mutants, examining roughly 30,000 colonies per lineage. We obtained 439 and confirmed about 100 independent DCR mutants from each lineage. These mutants 440 were pooled, total genomic DNA extracted and barcoded to specify each screening 441 background, and then sequenced en masse using Himar-1 transposon-specific 442 amplification and Illumina sequencing ([dataset] Onyeziri and Fuqua, 2021). We expected 443 to identify DCR mutations in the uppY gene for the $\Delta u p p W$ derivative, and mutations in $444 \quad$ uppW in the $\Delta u p p Y$ derivative, and multiple mutants in these genes were isolated as 445 predicted (Fig. 11, Table S3). Other previously identified genes from the initial DCR 446 screen were also re-isolated. For example, multiple independent mutants in uppE 447 (Atu1236) and uppC (Atu1238) were isolated in both mutant backgrounds. However, no 448 transposon insertions in any of the other genes in the uppABCDEF cluster were isolated 449 in either screen, despite the isolation of mutants in $u p p B$ and $u p p D$ in the prior screen 450 (Fig. 11). The two flippase homologs, uppX and uppV were isolated in both screening 451 backgrounds, although as observed before, considerably more mutants were isolated in 452 uppX. Overall, multiple transposon mutations were re-isolated in both the $\Delta u p p Y$ and $453 \Delta$ uppW screening backgrounds in 12 different upp genes that had been identified in the 454 prior screen, (Fig. 11, paired green and red bars; Table S3). Several other genes were 455 identified in both screens that had not been previously associated with UPP biosynthesis, 456 notably a galE/exoB homolog (ATU_RS19470), a traA plasmid conjugation gene homolog 
(ATU_RS22800, located on the linear chromosome), several predicted regulators (see below), and two genes of unknown function (ATU_RS15030 and ATU_RS22740).

\section{Genes identified in only one of the polymerase mutants}

The only upp genes other than uppY and uppW that had been identified before, which were isolated in only one of the pathway-specific screens, were uppG and $u p p H$. They were identified multiple times in the $\Delta u p p Y$ mutant but not once in the $\Delta u p p W$ mutant (Fig. 11, single red bars, Table S3). As described, UppG encodes a glycosyltransferase in the GT4 family, whereas uppH is a Class 10 glycoside hydrolase. Given the polarity of transposon insertions in uppH on uppG that we had already confirmed, it is very likely that the DCR phenotype in the $u p p H$ transposon mutants was due to their effect on uppG expression. Thus, uppG is probably the only established UPP biosynthesis function in addition to the uppW polymerase that is required specifically for UPPGINN production and does not appear to play a prominent role in UPPGalN production (at least in the $\Delta u p p Y$ background). However, another polysaccharide related gene we have now designated uppZ (ATU_RS11500) encoded convergently from the uppW Wzy-type gene, was disrupted in three independent sequences. UppZ is an OafA homolog similar to ExoZ, required for production of acetylated succinoglycan (Reuber \& Walker, 1993). Two additional genes were identified only in the $\Delta u p p Y$ screen. Four mutants were isolated in ATU_RS05430, predicted to be a fatty acid biosynthesis gene. Nine independent mutations were isolated in the podJ gene (ATU_RS02460), a polarity determination factor known to be required for normal polar localization of the C. crescentus holdfast (Hinz et al., 2003) and required for functions related to polar cell division in A. tumefaciens 
480 (Anderson-Furgeson et al., 2016). No podJ mutants were identified in the $\Delta u p p W$ 481 background.

Transposon mutants in 11 different genes were isolated specifically in the $\Delta u p p W$ mutant that resulted in loss of the CR phenotype imparted by the UPPGalN polysaccharide

(Fig. 11, single green bars, Table S3). Although these genes were independently disrupted in multiple DCR transposon mutants, the majority were isolated in fewer than 5 mutants. Two genes with transposon insertions from the $\Delta u p p W$-specific screen are adjacent, and annotated as rfbA (ATU_RS21635) and rfbD (ATU_RS21640), encoding a glucose-1-phosphate thymidylyltransferase and a dTDP-4-dehydrorhamnose reductase. L-rhamnose, often a component of O-antigen synthesis for LPS in members of the synthesis. The nuoL gene (ATU_RS06310) and clpA (ATU_RS06730) encode a NADH ubiquinone oxidoreductase subunit, and the ATP-binding subunit of the Clp protease. Seven of the genes identified are hypothetical reading frames.

\section{Genes involved in sugar-nucleotide precursor synthesis}

497 Multiple independent mutants were isolated in the exoC gene (ATU_RS19035), in both

499 described earlier, exoC encodes a phosphoglucomutase, predicted to convert glucose-6500 phosphate to glucose-1-phosphate, a precursor of sugar nucleotide substrates for

501 polysaccharide biosynthesis (Kamoun et al., 1989). However, a gene annotated as galE/exoB (ATU_RS19470) was not isolated in the original screen, but was isolated with 
5035 or more independent transposon mutants in both pathway-specific screens. This gene

504 is predicted to encode a UDP-glucose epimerase, similar to GalE, that catalyzes the

505 reversible epimerization reaction of the sugar nucleotide precursor UDP-GIcNAc to UDP-

506 GalNAc, and has an NADP Rossman domain (Holden et al., 2003). Given that we

507 distinguish the two polysaccharides by the presence of GIcNAc and GalNAc, the role for

508 this enzyme may be particularly relevant to the separation between pathways.

\section{Additional regulators identified in the pathway-specific screen}

511 Several probable regulatory genes were identified in the UPPGIcN and UPPGalN specific

512 screen (Fig. 11, Table S3). Mutations in three of these were identified in both screens.

513 The exoR gene (ATU_RS08400), encodes a periplasmic regulator of the ChvG-Chvl two-

514 component system (Heckel et al., 2014). In A. tumefaciens, exoR mutations dysregulate

515 hundreds of genes, including those for synthesis of the polysaccharide succinoglycan.

516 Mutations in exoR were also isolated as DCR mutants in the original screen (Xu and

517 Fuqua, unpublished results). The two other putative regulators identified had not been

518 implicated from the earlier screen. In both the $\Delta u p p Y$ and $\Delta u p p W$ backgrounds, mutations

519 were isolated for a homologue of the relA/spoT gene (ATU_RS05105) predicted to direct

520 synthesis and degradation of the (p)ppGpp stringent response signal in $A$. tumefaciens

521 (Zhang et al., 2004). The relA/spoT gene is predicted to be monocistronic. Likewise,

522 multiple mutations in both backgrounds were also isolated in a gene annotated as ntrY

523 (ATU_RS07130), encoding a predicted two-component sensor kinase homologue,

524 located immediately upstream of a two-component response regulator annotated as $n t r X$ 525 (ATU_RS07135). 


\section{Conservation of UPP biosynthesis genes}

527 We used translated sequences of the UPP genes identified in this study as queries to

528 search for homologs among the large number of genome sequences of members of the

529 Rhizobiaceae. It is recognized that rhizobia and agrobacteria are polyphyletic and

530 intermixed (Slater et al., 2009). Members of the Agrobacterium genus were historically

531 classified into three primary biovars (I, II, and III), based on multiple attributes, and many

532 of the wide host range $A$. tumefaciens strains including C58 are in Biovar I (Morton \&

533 Fuqua, 2012b). Recent phylogenetic studies have also divided the $A$. tumefaciens group

534 itself into over 20 separate genomospecies (Lassalle et al., 2011). A. tumefaciens C58,

535 the type strain we use in this study, is in Genomospecies 8 (G8, also given the species

536 designation $A$. fabrum). There is now a wealth of genomic data for comparison across the

537 agrobacteria and among the wider Rhizobiaceae that allows great insights into the genetic

538 conservation and ecological context among these bacteria (Weisberg et al., 2020).

A comparison of the UPP genes identified in the current study across

representative genome sequences reveals multiple interesting trends. Several of the

genes are widely conserved in sequence and synteny (Fig. S7, S8). First, the uppA-F

542 gene cluster is conserved largely throughout the agrobacterial genomospecies, with

543 UppA less well conserved but still present (Fig. S7). This gene cluster is fully or partially

544 conserved across the Rhizobiaceae, including among bacteria such as Rhizobium

545 leguminosarum and Rhodopseudomonas palustris that are both recognized to make a

546 UPP-type structure (Fritts et al., 2017, Williams et al., 2008). Beyond the Rhizobiaceae

547 the gene cluster is also partially conserved more widely in Brucella abortus and other

548 mammalian pathogens in the Alphaproteobacteria group. The uppA- $F$ cluster shares 
some similarity to the holdfast synthesis ( $h f s)$ gene cluster from $C$. crescentus, but is clearly divergent between bacteria in the Orders Rhizobiales and the Caulobacterales (Fritts et al., 2017).

Other UPP genes that are well conserved across the agrobacteria genomospecies are UppV and UppQ, the flippase and acetyltransferase encoded within a presumptive operon, and the UppP outer membrane protein. The sugar nucleotide enzyme ExoC and a GalU homolog (ATU_RS17570) encoded convergently with uppP (but not identified in our genetic screens) are also well conserved across the agrobacteria and the rhizobia. Strikingly, the uppG-O and uppXY gene clusters, and uppW gene are well conserved within the genomospecies considered Biovar I (G1, G2, G3, G4, G5, G7, G7-2, G8, G9, G13), with a few exceptions for specific genes within the clusters, but are largely absent outside of these taxa.

\section{Discussion}

In this study, we identified and analyzed a large number of genes required for biosynthesis of the A. tumefaciens unipolar polysaccharide known as the UPP, and in so doing, have discovered that this structure is composed of two genetically and biochemically discrete polysaccharides.

\section{Genetic screens provisionally identify UPP biosynthetic genes}

One of the two separable biosynthetic pathways is UppW-dependent, and drives synthesis of the UPP species that labels with the WGA lectin specific for GlcNAc residues (UPPGICN). The other pathway is UppY-dependent and directs production of the UPP 
572 species that labels with the DBA and PNA lectins specific for GalNAc residues (UPPGaIN).

573 Our genetic approach defined a large number of genes implicated in UPP synthesis,

574 identifying multiple components of a presumptive Wzx/Wzy pathway including formation

575 of sugar nucleotide precursors (Fig. 12), several regulators and a collection of genes of

576 unknown function. These screens were remarkably specific for UPP deficiencies, and

577 creation of in-frame deletions in many of the genes identified from the screen revealed

578 clear defects in UPP-dependent phenotypes in wild type and re-constructed screening

579 backgrounds. For our first DCR screen in which the uppY and uppW genes were intact,

580 the majority of genes identified were predicted polysaccharide-related functions (Fig. 2

581 and Table S1), with the exception of $u p p P$, which has the sequence of an outer membrane

582 protein with no predicted role in polysaccharide biosynthesis, and two genes of unknown

583 function, uppK and uppN. Only three of the disrupted genes identified in DCR mutants

584 within the genetic clusters predicted to encode Wzx-Wzy-type pathway components,

585 failed to impact UPP-dependent phenotypes when the corresponding in-frame deletions

586 were generated $(\Delta u p p K, \Delta u p p O, \Delta u p p H)$ in otherwise wild type $A$. tumefaciens.

587 Transposon insertions in uppH were polar on the downstream glycosyltransferase uppG,

588 although the evidence suggests the UppH glycoside hydrolase recognizes the UPP

589 structure. The incongruity between the uppK and uppO transposon mutants and in-frame

590 deletion mutants in these genes is however not explained by simple polarity, and the basis

591 for these differences requires further investigation. 


\section{Initial steps in UPP precursor synthesis}

596 The genes we have identified represent all of the requisite components of a complete 597 Wzx/Wzy-type polysaccharide biosynthesis pathway (Whitfield et al., 2020), including 598 homologs to flippases (Wzx-type proteins, UppX and UppV) and polymerases (Wzy-type 599 proteins, UppY and UppW) (Fig. 12). Our preliminary model is that UppE functions as the

600 WbaP initiating glycosyltransferase for UPP biosynthesis, or PHPT 601 (polyisoprenylphosphate hexose-1-phosphate transferase), adding the first 602 monosaccharide to an undecaprenol pyrophosphate (Und-PP) lipid carrier. Our prior 603 studies found that under phosphorus $\left(\mathrm{P}_{\mathrm{i}}\right)$ limitation, the requirement for uppE could be supplanted by another PHPT-type protein Atu0102 (Xu et al., 2012), but under Pi-replete 605 conditions as used in the current study, the role for UppE is clear. Interestingly, multiple 606 PHPT homologs are redundantly functional in holdfast biogenesis in C. crescentus (Toh 607 et al., 2008).

As with other polysaccharide biosynthetic pathways, precursors for this and subsequent monosaccharide additions are supplied by cytoplasmic sugar nucleotide pathways that in A. tumefaciens and its relatives, depend upon ExoC to convert glucose-

611 6-phosphate (Glc-6-P) to glucose-1-phosphate (Glc-1-P) (Kamoun et al., 1989). As 612 GlcNAc appears to be a major component of the UPP, we predict Glc-1-P is acetylated 613 to form $N$-acetyl glucosamine-1-phosphate (GlcN-1-P) by one of the putative acetyl 614 transferases, UppA or UppQ (Fig. 12), mutations in either of which cause severe UPP 615 defects. The GIcNAc would be conjugated to UDP, to form UDP-GIcNAc, although it is 616 possible that UDP linkage occurs prior to acetylation. Our genetic screens did not identify 617 any UTP-glucose-1-phosphate uridylyltransferases as DCR mutants, but the genes 
annotated exoN (ATU_RS18920) and galU (ATU_RS16570), which is encoded adjacent to uppP are both predicted to catalyze this reaction and are non-essential (Curtis \& Brun, 2014), so it is possible they are functionally redundant for this activity. The GalE homolog (ATU_RS19470) identified with a general UPP defect in our pathway-specific screen (Fig. $11,12)$ is predicted to reversibly epimerize UDP-GIcNAc to UDP-GalNAc, an interesting activity since these sugar moieties are likely to be defining residues for the UPPGIcN and UPPGalN polysaccharides, respectively. Furthermore, sugar-nucleotide precursors for UPP synthesis are likely to be generated through these basal sugar-nucleotide pathways, although no additional genes annotated to function in this capacity were identified.

Following the Wzx-Wzy general model, after addition of the initiating monosaccharide to the Und-PP carrier to form monoglycosylated Und-PP, other glycosyltransferases utilize sugar-nucleotide precursors to add monosaccharides to form the mature subunit (Whitfield et al., 2020). Generally, the first of these monosaccharide additions is mediated by a glycosyl transferase homologous to WecG/TagA, generating the diglycosylated lipid II intermediate, which can then be acted upon by additional glycosyl transferases (Ginsberg et al., 2006) Five predicted glycosyltransferases were identified in one or both of our genetic screens (uppD, uppG, uppl, uppJ and uppL). UppL is predicted to encode a glycosyltransferase (CAZy Group GT26) homologous to WecG and TagA, and is strictly required for UPP synthesis. It is also the best match to the HfsJ glycosyl transferase of $C$. crescentus, a WecG/TagA type protein required for holdfast synthesis and a point in the pathway at which holdfast production is regulated (Fiebig et al., 2014). We hypothesize that UppL generates the Lipid II diglycosyl intermediate for 
640

641

642

643

644

645

646

647

648

649

650

651

652

653

654

655

656

657

658

659

660

661

662

UPP biosynthesis. The four additional GTs can then act to assemble the UPP repeating subunit (Fig. 12).

The uppl, uppJ, and uppL genes clearly all play roles in UPP synthesis, as they were consistently identified in our DCR mutant screens and in-frame deletions have significant impact on UPP production and attachment. The uppD gene was identified as

a DCR mutant in our initial screen with uppY and uppW intact (in all four ECR screening backgrounds) and the $\triangle u p p D$ mutant is clearly biofilm deficient and greatly diminished for UPP production. However, it was not identified in the pathway-specific screen, suggesting that the requirement for UppD may be less stringent. Given our evidence for a UPP ${ }_{\text {GIcN- }}$ specific role for UppG, we propose that it adds a particular residue that acts to divert a portion of the growing subunits to the UppW-dependent pathway, whereas UPP subunits in which this additional residue is not incorporated proceed through the UppY-dependent pathway. Additional modifications to the UPP subunits may include more acetylation given the three potential acetyl transferases we have identified, UppA, UppQ, and UppZ.

\section{Translocation, polymerization and export of the UPP.}

A defining step in Wzx-Wzy pathway is translocation of the mature repeating subunit linked to Und-PP from the cytoplasmic face of the inner membrane to its periplasmic face (Islam and Lam, 2014). Mutants in uppX, encoding a predicted flippase with 10-12 transmembrane domains, have a severe UPP deficiency and were identified repeatedly in our screens. In addition, the upp $V$ gene also encodes a flippase homolog, that was consistently identified (albeit less frequently than uppX, see Figs. 2 and 11 and Tables S2 and S3) and also manifests a pronounced UPP defect. Our initial prediction 
663 that each flippase would be specific for one of the two polymerases did not hold true, as each flippase manifests defects for both UppW- and UppY-dependent polysaccharides. We therefore tentatively assign both UppX and UppV as flippases in our model, with perhaps UppX playing the primary role (Fig. 12).

Once in the periplasm, the UPP subunits initiate or add to the growing polysaccharide chain by the activity of either UppW or UppY, which are strictly required 669 for UPPGicN and UPPGalN, respectively (Fig. 12). We predict that the specific 670 monosaccharide composition of the subunit dictates which polymerase drives chain elongation. Addition of the subunit to the growing chain associated with its cognate

672 polymerase, releases the Und-PP which is then available to serve for the multiple other 673 pathways that depend on it, such as for synthesis of peptidoglycan and other 674 polysaccharides.

Based on the Wzx/Wzy paradigm, the UPP polysaccharide then associates with a periplasmic co-polymerase (PCP, Wzc) and is ushered to the outer membrane

677 polysaccharide secretin (OPX, Wza) for export to the cell exterior (Whitfield et al., 2020).

678 The details of this process and the specific role for the PCP remain ill-defined for any 679 biosynthetic pathway, but it is clear that the PCP and OPX proteins form a large multimeric 680 complex that spans the outer membrane, and the periplasm, projecting into the cytoplasm 681 (Collins et al., 2007). Our genetic analysis suggests that the predicted PCP-2a proteins, 682 UppM and UppB, fulfill the PCP (Wzc) requirement for both UPP polysaccharides and 683 that UppC functions as the OPX (Wza) secretin (Fig. 12). Other important processing may 684 occur in the periplasm, such as the activity of the periplasmic glycoside hydrolase UppH 685 (although this is not required for UPP production) and perhaps linkage of the UPP 
686

687

688

689

690

691

692

693

694

695

696

697

698

699

700

701

702

703

704

705

706

707

708

polysaccharide to LPS via the O-antigen ligase UppF (also see below). What retains the externalized UPPGIcN and UPPGalN at discrete locations at a single pole remains to be determined. Our preliminary results suggest that several of the UPP biosynthetic proteins identified here localize to the same pole as the UPP (Natarajan and Fuqua, unpublished) suggesting that at least some of the steps of biosynthesis occur proximal to the eventual site of UPP elaboration, similar to what has been observed for holdfast biogenesis in $C$. crescentus (Javens et al., 2013). A role for the PodJ polar localization factor in proper localization of the UPP to the pole is supported by its identification in our genetic screens (Fig. 11).

The pathway specific screen identified a significant number of genes in which multiple independent transposon insertions resulted in the DCR phenotype indicative of UPP deficiencies, that had not been identified in the initial screen with uppY and uppW intact. Some of these genes are annotated to be related to polysaccharide biosynthesis ( $r f b B, r f b D$, and exoZ), predicted regulators (relA, ntrY) or the polarity determinant podJ. It is unclear what role the other genes with annotations either that predict functions outside of polysaccharide synthesis or hypothetical genes, might play in UPP synthesis. Although the isolation of multiple independent mutants supports their impact on UPP synthesis, more extensive genetic analysis is required to conform their roles.

\section{Anchoring and cohesiveness of the UPP}

Interestingly, individual in-frame deletions of all of the uppA-F genes result in UPP deficiencies although no mutations were identified for uppA or uppF in any of the DCR genetic screens performed. UppA encodes a cytoplasmic GNAT-type acetyl transferase. 
709 For several bacterial polysaccharides, the degree and distribution of acetylation is thought

710 to alter the adhesiveness of the polysaccharide (Vuong et al., 2004, Wan et al., 2013).

711 UppA may modulate adhesiveness of the UPP, but its loss may not visibly impact the CR-

712 staining properties of the UPP. There is a strict requirement for the other cytoplasmic

713 GNAT-type protein UppQ for the ECR phenotype, and so we speculate that UppA

714 performs a non-critical role such as UPP modification, but we do not know with certainty,

715 so both UppA and UppQ are depicted to modify the UPP (Fig. 12). The uppZ gene

716 identified in the pathway-specific screen performed with the $\Delta u p p Y$ mutant, also encodes

717 a predicted acetylase, but this was only identified in the $\Delta u p p Y$ mutant suggesting 718 specificity for the UPP ${ }_{\text {GICN }}$ polysaccharide.

UppF is of particular interest, as it encodes a homolog of O-antigen ligases that

720 function in attaching the O-antigen portion of LPS to the LPS core sugars during

721 biogenesis of this outer membrane component (Ruan et al., 2018). The dramatic biofilm

722 and attachment deficiencies for the $\Delta u p p F$ mutant suggest a profound UPP defect, but it

723 was not identified in either of the DCR screens. In C. crescentus, the holdfast is attached

724 to the tip of the stalk via the holdfast anchor (Hfa) proteins, that are thought to form a $\beta$ -

725 amyloid-type fiber (Hardy et al., 2010). However, there are no clear homologs of the Hfa

726 proteins encoded by A. tumefaciens and we speculate that instead the UPP may be linked

727 to LPS on the cell surface. Given its combination of phenotypes, UppF is a promising 728 candidate for linking the UPP to LPS. 


\section{The polysaccharide component of the $A$. tumefaciens UPP}

733 As with the C. crescentus holdfast, the UPP structure was first detected using lectin

734 reagents that are generally specific for polysaccharides (Tomlinson \& Fuqua, 2009).

735 Lectin labeling remains the most facile and reliable way to identify the $A$. tumefaciens

736 UPP microscopically, although it is also visible in TEM and SEM without specific labeling

737 (Xu et al., 2013). As discussed above, our genetic analyses have identified many genes

738 that are required for UPP biosynthesis, and the majority of these can be linked to

739 polysaccharide-related functions, specifically for Wzx-Wzy-type pathways. We have also

740

741

742

743

744

745

746

747

748

749

750

751

752

753

754 identified several regulators and the polar localization factor PodJ as important for UPP

biosynthesis. Our pathway-specific screen identified a significant number of genes of unknown function, which may or may not be related to polysaccharides, and remain to be investigated further. The UppP protein, predicted to encode an outer membrane porin (distinct from polysaccharide secretins such as UppC), is not a typical component of a Wzx/Wzy pathway, but is required for UPP production. Despite these few exceptions, the prominent role for Wzx/Wzy proteins and other polysaccharide related proteins (e.g. sugar nucleotide precursors) strongly support the conclusion that the UPP is predominantly comprised of polysaccharide.

We have added to this evidence by finding that the extracellular addition of the purified UppH glycoside hydrolase degrades all visible lectin-binding UPP material on pre-attached cells, and can inhibit biofilm formation when co-incubated with planktonic $A$. tumefaciens. The $\mathrm{UppH}$ protein is annotated in the $A$. tumefaciens C58 genome as a xylosidase (Goodner et al., 2001, Wood et al., 2001), and a recent study, tentatively designating the gene $x y n A$, found that it was required for growth on minimal medium with 
exogenous xylan as a carbon source (Mathews et al., 2019). Our observations on susceptibility of both UPPGIcN and UPPGalN to UppH (XynA) activity suggest that the enzyme hydrolyzes important glycosidic linkages common to both UPP polysaccharides. Based on its activity on exogenous xylan and its annotation, we hypothesize that these vulnerable positions within the UPP contain xylose residues. A recent chemical characterization of the $C$. crescentus holdfast revealed that it contains xylose residues, among other monosaccharides (Hershey et al., 2019). The $\Delta u p p H$ mutant does not have a detectable attachment phenotype, but this is a relatively common observation among periplasmic glycoside hydrolases associated with polysaccharide synthesis pathways (Baker et al., 2016). The roles for these enzymes in polysaccharide biosynthesis remain ill-defined despite their utility as purified reagents with high specificity for their cognate polysaccharides, and their anti-biofilm potential. We propose that $\mathrm{UppH}$ is a component of the UPP biosynthetic machinery that is active on the polysaccharide component of this structure. Interestingly, although exogenous UppH incubation clearly removes the UPP as visualized with lectin labeling and TEM, pre-attached cells remain on surfaces after treatment, and there is incomplete biofilm inhibition in the presence of $\mathrm{UppH}$. This may reflect a curing process of the UPP, as has been observed for the $C$. crescentus holdfast (Hernando-Perez et al., 2018) to a glycosidase resistant, sterically blocked form, or alternatively the function of an as yet unidentified component that is resistant to the $\mathrm{UppH}$ enzyme.

Given the number of genes encoding Wzx-Wzy components that are required for both UPP ${ }_{\text {GICN }}$ and UPPGalN synthesis, and their mutual susceptibility to the UppH glycoside hydrolase, we hypothesize that they have closely related structures and perhaps a 
778 common core motif. Two related UPP polysaccharides would be similar to the Vibrio cholerae VPS polysaccharide which occurs as two distinct species, one which contains a-d-Glucose among other monosaccharides, and another less abundant species where

781 this residue is $\alpha-d-G l c N A c$ (Yildiz et al., 2014). The lectin specificity of the two UPP species suggests that one species contains GlcNAc and the other GalNAc, but this remains to be proven by chemical characterization of the two different polysaccharides. Interestingly, the only annotated biosynthetic genes other than the polymerase genes uppW and uppY that are specific for each polysaccharide, are uppG, encoding a glycosyltransferase uppZ, an exoZ homolog, both involved in UPPGIcN synthesis but not $U_{\text {UPalN }}$, and potentially the $r f b A$ and $r f b D$ homologs specific for UPPGalN and not UPP GIcN. $_{\text {. }}$ The observation that the $\triangle u p p G$ mutant synthesizes a very small UPP, but still detectable with WGA, suggests that it is not solely responsible for addition of GlcNAc residues. We speculate that UppG may either contribute to addition of GlcNAc residues, or other eventual elaboration of UPP ${ }_{G I N}$. Wzy-type polymerases can be highly specific, and subtle differences in the linkages and monosaccharides can dictate recognition between particular Wzy-type proteins (Hong et al., 2015). The role of the uppZ in UPP synthesis

795 remains to be investigated more fully.

\section{Physical separation of UPPGIcN and UPPGalN at cell poles}

798 The sectored, bullseye pattern observed for lectin labeling when cells producing the UPP 799 are incubated with both the DBA and WGA lectins suggests that the UPP GlcN $_{\text {and UPPGaIN }}$ 800 polysaccharide species are localized differently relative to each other (Fig. 6). The DBA 
801 labeling is usually proximal to the tip of the cell, whereas the WGA labeling, while still 802 unipolar, is more diffuse and visibly surrounding the DBA-labeled material. This pattern suggests that these polysaccharides may be localized to specific positions around the pole. Alternatively, they may be extruded from the same point on the pole, but are temporally synthesized in stages. How the roles for these multiple polysaccharide species

806 are integrated during the surface attachment process, and how their biophysical properties may differ are current topics of investigation.

\section{Mixed conservation among the UPP biosynthesis genes}

The six gene uppABCDEF cluster we initially identified is fully or partially

818 produces a UPP-type structure that labels with WGA and presumably contains GIcNAc

819 residues, but only the uppA-F cluster is conserved (with the uppC secretin in a different

820 position), and a flippase has yet to be identified (Fritts et al., 2017). In C. crescentus, the

821 holdfast was initially defined by WGA binding and is now know to contain GlcNAc, xylose,

822 and other monosaccharides (Hershey et al., 2019), and A. tumefaciens homologs to the

$823 h f$ genes reside in the uppA-F cluster, as well as others outside, such as the glycosyl 
824 transferases uppJ and $u p p L$, which are similar to $h f s L$ and $h f s J$, respectively. In $R$.

825

826

827

828

829

830

831

832

833

834

835

836

837

838

839

840

841

842 843 tryptone, $5 \mathrm{~g}$ of yeast extract and $5 \mathrm{~g}$ of $\mathrm{NaCl}$ per liter, $\mathrm{pH}$ 7.0) or AT minimal medium 844 (Tempé et al., 1977) with $0.5 \%$ (w/v) glucose and $15 \mathrm{mM}$ ammonium sulfate to make 845

leguminosarum, the uppA-F cluster (designated as gms genes for glucomannan synthase) is conserved and syntenous with that from $A$. tumefaciens, but the glucomannan unipolar polysaccharide it directs production of is composed of glucose and mannose and is recognized by host pea plants via a specific lectin (Laus et al., 2006, Williams et al., 2008). Clearly, diversification of these genes has led to production of different polysaccharides, with niche-specific functions. Over evolutionary history, several A. tumefaciens lineages within the Biovar I type strains have apparently bifurcated their UPP into two different chemical species, UPP ${ }_{\text {GICN }}$ and UPPGalN, by the activity of an expanded and intertwined gene set that drives their synthesis. The UPP genes in general provide a fascinating example for diversification of cell surface polysaccharides, features that are arguably very much exposed to environmental selective pressures. The specific roles for the expanded UPP genes in the ecological context of the A. tumefaciens Biovar I lineages, including but not restricted to plant interactions, is an area of future interest.

\section{Experimental Procedures}

Strains, plasmids, and reagents. The bacterial strains and plasmids used in this study are listed in Table S4. Oligonucleotide sequences are available upon request. $A$. tumefaciens strains were grown at $28^{\circ} \mathrm{C}$ or $30^{\circ} \mathrm{C}$ on liquid or solid LB (10 g of BactoATGN. For biofilm assays, $22 \mu \mathrm{M} \mathrm{FeSO} 4$ was added to the liquid ATGN medium immediately before inoculation, and for sacB counter-selection, $2.5-5 \%(\mathrm{w} / \mathrm{v})$ sucrose 
847 replaced glucose as the sole carbon source to make ATSN. For ATGN-CR, the CR dye 848 was dissolved in Milli-Q water (Millipore Sigma, Burlington, MA) to a concentration of 20 $849 \mathrm{mg} / \mathrm{ml}$, then passed through a $0.2 \mu \mathrm{m}$ filter to remove aggregates. $250 \mu \mathrm{l}$ of this stock 850 solution was added per $100 \mathrm{ml}$ ATGN solid medium to make a final concentration of 50 $851 \mu \mathrm{g} / \mathrm{ml}$ ATGN-CR. E. coli strains were grown at $37^{\circ} \mathrm{C}$ in LB medium. Motility assays were 852 performed in $0.3 \%$ ATGN agar in $60 \mathrm{~mm}$ plates, inoculated in the center of the medium 853 with the tested strain, and incubated at $30^{\circ} \mathrm{C}$. Plasmids were introduced into chemically

854 competent cell preparations of $E$. coli, and into $A$. tumefaciens via conjugation or 855 electroporation (Morton \& Fuqua, 2012a). Oligonucleotide primers were obtained from Integrated DNA Technologies, Coralville, IA, and single-primer extension DNA sequencing was performed by ACGT, Inc., Wheeling, IL. Chemicals, antibiotics, and culture media were obtained from Fisher Scientific and Sigma-Aldrich. When necessary, antibiotics were added to the medium as follows: $100 \mu \mathrm{g} / \mathrm{ml}$ ampicillin (Ap), $50 \mu \mathrm{g} / \mathrm{ml}$ 860 gentamycin $(\mathrm{Gm})$ and $50 \mu \mathrm{g} / \mathrm{ml}$ kanamycin $(\mathrm{Km})$ for $E$. coli, and $300 \mu \mathrm{g} / \mathrm{ml} \mathrm{Gm}$ and $\mathrm{Km}$ for A. tumefaciens. $250 \mu \mathrm{M}$ Isopropyl- $\beta$-D-thiogalactopyranoside (IPTG) was used to 862 induce expression of plasmid borne genes unless otherwise stated. All fluorescently conjugated lectins were obtained from Invitrogen; FITC-labeled WGA (fl-WGA), 864 Alexafluor 594-labeled WGA (af-WGA), FITC-labeled DBA (fl-DBA),.

Controlled expression plasmids. Wild type coding sequences of genes to be expressed were amplified from $A$. tumefaciens C58 genomic DNA (unless otherwise stated), and cloned into the $\mathrm{Lacl}^{\mathrm{Q}}$ encoding, IPTG inducible plasmid pSRK carrying either a 869 gentamycin (pSRKGm) or kanamycin (pSRKKm) resistance cassette (Khan et al., 2008) 
870 using primers corresponding to each gene either by amplification with Phusion or Q5

871 polymerases (NEB) and ligation or isothermal assembly. Amplicons were introduced into

872 the appropriately cleaved plasmid and verified by PCR, restriction enzyme digestion and

873 sequencing.

874

875 Site specific mutagenesis. A slightly modified QuikChange mutagenesis protocol from

876 Stratagene was used to engineer site specific mutations in uppG and uppH. Briefly, two

877 complementary primers were designed with the required base pair mutation(s) flanked by

$878 \sim 15$ nt wildtype sequences on either side. A PCR reaction (16 cycles) using NEB Phusion

879 polymerase was used to generate cut plasmid derivatives with the modified sequences.

880 Correct amplification was verified via gel electrophoresis. $1 \mu$ of the methylation-

881 dependent restriction enzyme Dpnl was used to digest the methylated wildtype plasmid.

882 Digested product was transformed into E. coli and plasmid clones were purified and 883 sequenced to confirm the presence of the desired mutation.

885 In-frame markerless deletions. In-frame markerless deletions were constructed as 886 previously described (Morton \& Fuqua, 2012a, Xu et al., 2013). Upstream and 887 downstream $\sim 500$ bp regions flanking the genes to be deleted were amplified from $A$. 888 tumefaciens C58 genomic DNA using specific primers (P1 and P2 for upstream regions, 889 P3 and P4 for downstream regions) and NEB Phusion polymerase. Care was taken to 890 ensure the 5' and 3' ends of the genes were not altered, and that translational coupling 891 between linked genes was retained. Primers P2 and P3 were designed with reverse 892 complementarity in the 5' sequences allowing for single overlap extension (SOE) 
893 amplification of both genes into a single amplified product as described (Morton \& Fuqua,

894 2012a). The combined flanking regions were ligated into the appropriately cut suicide

895 vector pNPTS138 using isothermal assembly with the NEBuilder HiFi DNA Assembly

896 Cloning Kit to create a deletion construct which was subsequently transformed into

897 chemically competent S17-1/Apir E. coli. The pNPTS138 vector confers kanamycin

898 resistance $\left(\mathrm{Km}^{\mathrm{R}}\right)$ and sucrose sensitivity $\left(\mathrm{Suc}^{\mathrm{S}}\right)$ due to the presence of sacB. Introduction

899 of this plasmid into A. tumefaciens was via conjugation with S17- $\lambda$ pir E. coli. The ColE1

900 origin of pNPTS138 does not replicate in $A$. tumefaciens, and a single crossover event

901 allows plasmid integration into the chromosome, which was confirmed by patching

902 transformants on to ATGN-Km and ATSN to screen for $\mathrm{Km}^{\mathrm{R} S u c}{ }^{\mathrm{S}}$ strains. Strains that had

903 excised the plasmid were isolated by parallel patching on to ATSN and ATGN-Km to

904 screen for $\mathrm{Km}^{\mathrm{S} S u c}{ }^{\mathrm{R}}$ derivatives. Deletion of the target genes was confirmed by diagnostic

905 PCR using primers (P5 and P6) flanking the site of deletion.

906

907 Congo red growth assays. A. tumefaciens strains were grown in ATGN until mid908 exponential phase, normalized to an OD600 of 0.05 , and $2 \mu$ spotted on to ATGN-CR 909 plates with or without IPTG. Plates were incubated at $30^{\circ} \mathrm{C}$. Photographs of spots were 910 taken following incubation for $48 \mathrm{~h}$.

912 Biofilm assays. Strains of $A$. tumefaciens were grown and analyzed as previously 913 described (Morton \& Fuqua, 2012c). Briefly, PVC coverslips were inserted vertically into 914 the wells of 12-well polystyrene plates (Corning Inc.) and UV sterilized. The wells were 915 subsequently filled with $3 \mathrm{ml}$ mid-exponential phase cultures (with or without IPTG) 
916

917

918

919

920

921

922

923

924

925

926

927

928

929

930

931

932

933

934

935

936

normalized to OD600 0.05. The 12-well plates were incubated in static conditions for 48 or $72 \mathrm{~h}$ at room temperature or $30^{\circ} \mathrm{C}$ inside a plastic Tupperware containing an open bottle of saturated $\mathrm{K}_{2} \mathrm{SO}_{4}$ solution to maintain humidity. Following incubation, the coverslips were rinsed with sterile water and stained with $0.1 \% \mathrm{w} / \mathrm{v}$ crystal violet $(\mathrm{CV})$ solution $0.1 \%$ $w / v$ for 20 min. Stained coverslips were rinsed with sterile water and then submerged in weigh boats containing $1 \mathrm{ml} \mathrm{33 \%}$ acetic acid to solubilize the CV. Quantification was performed by measuring soluble A600 CV absorbance using a Biotek Synergy HT microplate reader and Gen 5 software (Biotek, Winooski, VT). Values were normalized to culture growth by dividing by final culture OD600.

UPP production assays. UPP was visualized using the WGA lectin conjugated to Alexa fluor 594 (af-WGA, Invitrogen) and FITC (fl-DBA). $1 \mathrm{ml}$ of mid-exponential phase $A$. tumefaciens cultures were spun down $(7000 \times \mathrm{g})$, washed twice with ATGN, pelleted, and resuspended in $100 \mu \mathrm{l}$ ATGN. $1 \mu \mathrm{l}$ of $1 \mathrm{mg} / \mathrm{ml}$ the fluorescent lectin stock was added to the suspensions and incubated at $28^{\circ} \mathrm{C}$ for $20-40 \mathrm{~min}$. 1-2 $\mu$ labeled suspensions were placed on microscope slides containing agarose pads (1-1.5\% agarose, $100-200 \mu l)$. Coverslips were placed on top of the pads, and samples were visualized by fluorescence microscopy using either a Nikon E800 camera with a 100X oil immersion objective or a Nikon Eclipse Ti-2 microscope with a Hamamatsu ORCAFlash 4.0 camera and a 60X oil immersion objective and NIS-Elements Software. Images were analyzed with Nikon Elements software and Fiji (Schindelin et al., 2012). 
Short term attachment and lectin binding assays. Short term binding assays were carried out as previously described (Morton \& Fuqua, 2012c). Briefly, glass coverslips were placed horizontally inside the wells of 6 -well plates and submerged in $2 \mathrm{ml}$ midexponential phase cultures of $A$. tumefaciens strains. Plates were incubated statically 2 $\mathrm{h}$ at room temperature to allow cells to swim to and bind the coverslip. Following 943 incubation, cultures were aspirated, and coverslips washed twice in ATGN to remove 944 unattached cells. Coverslips were then placed over $100 \mu \mathrm{l}$ of $1: 100$ dilution $(10 \mu \mathrm{g} / \mathrm{ml}$ final $)$ $945 \mathrm{fl}-\mathrm{WGA}$, afWGA, or fl-DBA, or two in combination for dual lectin binding. Coverslips were 946 allowed to stain $1 \mathrm{~h}$, then rinsed twice in ATGN before placing them either on a 947 microscope slide or an agarose pad (1-1.5\% agarose, $100-200 \mu \mathrm{l})$. Visualization was 948 performed as with standard UPP production assays. For high resolution single cell microscopy, spinning disk confocal microscopy (SDCM) was used (Yokogawa CSU10 950 confocal, Nikon TE2000U microscope, Photometrics Cascade II 512B camera) with Metamorph software (Molecular Devices Corp., Sunnyvale, CA).

Electron microscopy. Electron microscopy was carried out at the Indiana Molecular 954 Biology Institute Microscopy Center. For Transmission Electron Microscopy (TEM) and 955 colloidal gold-labeled lectin, $1 \mathrm{ml}$ of mid-exponential phase culture was pelleted and resuspended in $200 \mu \mathrm{l}$ ATGN. $5 \mu \mathrm{l}$ of $20 \mathrm{mg} / \mathrm{ml}$ suspensions of $20 \mathrm{~nm}$ colloidal gold conjugated WGA or $10 \mathrm{~nm}$ gold conjugated PNA (EY Laboratories) were added to the suspension and incubated at room temperature for $20 \mathrm{~min}$. The labeled suspension was 959 pelleted at $6000 \times \mathrm{g}$ and washed twice with $1 \mathrm{ml} 10 \mathrm{mM}$ Tris-Cl, $\mathrm{pH} 8.0$ before resuspending in $10 \mathrm{mM}$ Tris- $\mathrm{Cl}, \mathrm{pH}$ 8.0. $10 \mu \mathrm{l}$ of the resuspension were placed on a 
961 formvar-coated copper grid for $5 \mathrm{~min}$ and stained with $10 \mu \mathrm{l}$ of $1 \%$ uranyl acetate for

962 another $5 \mathrm{~min}$. Filter paper was used to remove the excess uranyl acetate, and the grid

963 was air dried for 5 min before viewing using the JEOL JEM-1010 Transmission Electron

964 Microscope at $80 \mathrm{kV}$.

965

966 Purification of a His6-UppH protein. The uppH coding sequence (Atu2371) was

967 amplified from genomic DNA and fused downstream of the His6-tag coding sequence in

$968 \mathrm{pET}-15 \mathrm{~b}$ cleaved at the $\mathrm{Ndel}$ and BamHI restriction sites. The resulting plasmid pRN39

969 was transformed into chemically competent E. coli BL21-CodonPlus (DE3)-RIL cells

970 (Stratagene) and grown at $37^{\circ} \mathrm{C}$ with shaking in $200 \mathrm{ml}$ LB supplemented with Ap (100

$971 \mu \mathrm{g} / \mathrm{ml}$ ). At mid-exponential phase, His6-UppH expression was induced by addition of 200

$972 \mu \mathrm{M}$ IPTG and incubating for $4 \mathrm{~h}$. Cells were collected by centrifugation at 5,600 $\mathrm{g} \mathrm{g}$ for 20

973 minutes and stored at $-20^{\circ} \mathrm{C} .2 \mathrm{~g}$ of cells were thawed on ice, resuspended in $5 \mathrm{ml}$

974 extraction buffer (50 mM TES [(N-tris(hydroxymethyl)methyl-2-aminoethanesulfonic

975 acid)], $10 \mathrm{mM} \mathrm{MgCl} 2,10 \mathrm{mM}$ DTT, $\mathrm{pH}$ 7.0) and lysed using an M-110L Microfluidizer

976 Processor (Microfluidics, Westwood, MA). Following 10 min centrifugation (9,900 x g), a

977 significant fraction of the overexpressed tagged UppH was insoluble, but a fraction

978 remained soluble based on SDS-PAGE analysis. The supernatant with the soluble His6-

979 UppH was loaded on to a $3 \mathrm{ml}$ TALON Metal Affinity Resin (Clontech) equilibrated in

980 binding buffer (50 mM Na $\mathrm{HPO}_{4}, 300 \mathrm{mM} \mathrm{NaCl}, 10 \%$ glycerol, 10 mM imidazole, pH 8).

$9814 \mathrm{ml}$ of binding buffer containing increasing concentrations of imidazole (50 mM, $250 \mathrm{mM}$,

$982500 \mathrm{mM}$, and $1 \mathrm{M}$ ) were used to carry out step gradient elution. UppH was present in the

$983250 \mathrm{mM}$ imidazole fraction based on SDS-PAGE analysis and MALDI-MS of the excised 
984 band. The purified protein was dialyzed into $50 \mathrm{mM} \mathrm{Na} 2 \mathrm{HPO}_{4}, 100 \mathrm{mM} \mathrm{NaCl}, 10 \%$ 985 glycerol, pH 8. Protein concentration was determined by the molar absorptivity using bovine serum albumin as a standard and the enzyme was aliquoted and stored at $-80^{\circ} \mathrm{C}$ for future use. The same approach was used to purify His6-UppH E152Q E266Q.

Transposon mutagenesis and en-masse sequencing. Mutagenesis: donor $E$. coli SM10- $\lambda$ pir carrying the Himar1 plasmid pFD1 was grown in LB overnight until turbid. donor and recipient strains were collected in Eppendorf tubes, spun down at 5,600 x $\mathrm{g}$ for $1 \mathrm{~min}$, and the pellets resuspended in $50 \mu \mathrm{LB}$. Subsequently, $50 \mu \mathrm{l}$ of the donor strain was combined with $50 \mu \mathrm{l}$ of each of the recipient strains. Entire matings (100 $\mu \mathrm{l})$ were spotted on $0.2 \mu \mathrm{m}$ cellulose acetate filter paper on LB plates. Plates were incubated overnight at $28^{\circ} \mathrm{C}$ to allow for conjugative transfer. Cells were resuspended from the filter paper in $30 \%$ glycerol, serially diluted in $1 / 10$ increments, and frozen at $-80^{\circ}$. medium was prepared using $1.5 \mathrm{ml}$ of $2 \%$ stock solution of CR per $100 \mathrm{ml}$ ATGN. Plates 1002 also contained $300 \mu \mathrm{g} / \mathrm{ml} \mathrm{Km}$ for selection. $100 \mu \mathrm{l}$ of cell suspensions were plated on 1003 ATGN-CR-Kan plates at 1:100 dilution for CDGS- Upp+ $\Delta p r u A \Delta u p p Y$, and 1:1000 dilution 1004 for CDGS- Upp+ $\Delta p r u A \Delta u p p W$. Plates were incubated 48-72 $\mathrm{h}$ and screened for 1005 decreased CR (DCR) colony phenotypes. DCR colonies from the different strain 1006 backgrounds were picked, streaked or patched on fresh ATGN-CR-Kan plates and 
1007 incubated at $28^{\circ} \mathrm{C}$. PCR was used to confirm that the DCR mutants were $A$. tumefaciens 1008 and not $\mathrm{Km}^{\mathrm{R}}$ contaminants with a DCR phenotype. Biofilm assays on randomly selected

1009 DCR mutants showed deficiencies to varying degrees. Confirmed DCR strains were 1010 inoculated in $2 \mathrm{ml} \mathrm{ATGN-Kan}$, and $250 \mu \mathrm{l}$ from each stationary-phase culture was pooled 1011 together into $1 \mathrm{ml}$ batches. This was done separately for the two $A$. tumefaciens strain 1012 backgrounds. gDNA was extracted from pooled DCR cultures from the two strain 1013 backgrounds using (Promega gDNA extraction kit) and stored at $4^{\circ} \mathrm{C}$. Over 50,000 1014 colonies were screened collectively in both strain backgrounds, and roughly $0.5 \%$ were 1015 DCR mutants in each background.

1016 Sequencing library preparation: Illumina library construction was carried out for the two 1017 separate gDNA pools using the terminal deoxynucleotidyl transferase (TdT) tailing 1018 method (Deng and Wu, 1983). Briefly, a Covaris instrument was used to shear gDNA to 1019 200-700 bp fragments, and a Tape Station instrument was used to estimate sheared 1020 gDNA concentration (for this protocol, gDNA concentration was at least $69 \mathrm{ng} / \mu \mathrm{l}$ ). Several 1021 consecutive PCR reactions were carried out to perform TdT tailing, to append adaptors 1022 sequences needed for Illumina sequencing, and to append adaptors with unique 1023 barcodes to the separate libraries corresponding to the two $A$. tumefaciens strain 1024 backgrounds. Final reaction products were combined to be multiplexed and the library 1025 was further purified by passing through a PCR purification column (Edge Biosystems). The library was submitted to the IU Center for Genomics and Bioinformatics (CGB) 1027 for sequencing. Sequencing was performed on a NextSeq 500 using a 75-cycle single1028 end run. Reads were then mapped to the Agrobacterium tumefaciens C58 reference 1029 genome using bowtie2 (v2.3.5.1) with the following special parameters: --local -k 2. Only 
1030 reads that originated within the transposon (and started with AACCTGTTA allowing a 1031 single mismatch) and had uniquely mapped were kept and tallied to quantify transposon 1032 insertion rates.

1033

1034

Multi-locus sequence analysis (MLSA). Publicly available genome sequences from

1035 the Agrobacterium/Rhizobium group as well as select Sinorhizobium, Ensifer, 1036 and Kaistia strains were downloaded from NCBI GenBank on September 12, 2019.

1037 AutoMLSA with the default parameters and IQ-TREE v. 1.6.12 with the parameters "-bb 10381000 -alrt 1000" were used to generate a multi-locus sequence analysis (MLSA) tree 1039 (Davis et al., 2016, Nguyen et al., 2015). Twenty-three translated gene sequences (dnaK, 1040 prfC, hemN, haml, truA, glyS, coxC, ATU_RS03855, ATU_RS07710, hom, rplB, rpoC, 1041 rpoB, murC, hemF, ATU_RS12850, acnA, leuS, cgtA, secA, plsC, aroB, lysC) from the 1042 strain $A$. fabrum C58 (NCBI accession: GCA_000092025.1) were used as reference 1043 sequences for autoMLSA (Zhang et al., 2012). Protein sequences from the genome of $A$. 1044 tumefaciens (fabrum) C58 for the loci ATU_RS02360, ATU_RS02370, ATU_RS06100, 1045 ATU_RS06105, ATU_RS06110, ATU_RS06115, ATU_RS06120, ATU_RS06125, 1046 ATU_RS06130, ATU_RS11495, ATU_RS11500, ATU_RS11550, ATU_RS11555, 1047 ATU_RS11560, ATU_RS11565, ATU_RS11570, ATU_RS11575, ATU_RS11580, 1048 ATU_RS11585, Atu2378 (no annotation in NCBI), ATU_RS11590, ATU_RS16315, 1049 ATU_RS16320, ATU_RS17560, ATU_RS17565, ATU_RS17570, ATU_RS19030, 1050 ATU_RS19035, ATU_RS19040, ATU_RS26530, and ATU_RS16325 were used as 1051 queries in BLASTP v. 2.6.0+ searches of individual genomes; and the best blast hit was 1052 taken (Camacho et al., 2009). Top hit sequences were then used as queries in BLASTP 
1053

1054

1055

1056

1057

1058

1059

1060

1061

1062

1063

1064

1065

1066

1067

1068

1069

1070

1071

1072

1073

1074

1075

searches against a database of proteins from the C58 reference genome. Blast hits were filtered to those with $>50 \%$ query coverage and $>40 \%$ amino acid ID, and the best hit to C58 were identified. If the best hits of both searches were reciprocal best hits, the presence of that gene was confirmed in a genome. Phylogenies and heat maps were visualized using the $\mathrm{R}$ package ggtree (Yu et al., 2017). Gene synteny figures were generated using clinker v. 0.0.9 with the default options (Gilchrist \& Chooi, 2021).

\section{Acknowledgements}

We wish to acknowledge and Loralyn Cozy and Megan Lohmiller for help with initial work on the UPP, and Yves Brun and Ellen Quardokus for helpful discussions and suggestions. Ankur Dalia generously provided protocols and troubleshooting advice for transposon sequencing. Barry Stein was a great help with electron microscopy, performed at the Indiana University (IU) Electron Microscopy Center. We thank the Department of Botany and Plant Pathology at Oregon State University for its support of computing infrastructure.

T.D. was supported through an Indiana University-Purdue University Collaborations in Life Science and Informatics Research grant. M.E.H. received support from the IU Genetics, Cellular and Molecular Sciences NIH Training Grant (T32 GM007757). This project was supported by grants to C.F. from the NIH (RO1 GM120337), and the Indiana University META-Cyt Program funded in part by a major endowment from the Lilly Foundation, and to J.H.C. by the National Science Foundation (DEB-1738028). The funders had no role in study design, data collection and analysis, decision to publish, or preparation of the manuscript. 
1076

1077

1078

1079

1080

1081

1082

1083

1084

1085

1086

1087

1088

1089

1090

1091

1092

1093

1094

1095

1096

1097

1098

1099

1100

1101

1102

1103

1104

1105

1106

1107

1108

1109

1110

1111

Author contributions: C.F. formulated the research plan; M.O., R.N., G.H., J.X., I.R.,

J.K., T.D., M.H. and C.F. performed the experiments, J.C. and A.W. performed genomic

sequence analyses; C.F., M.O. and G.H. wrote the paper.

Data availability: High-throughput, Illumina-based transposon sequencing data is being deposited in the GEO database (([dataset] Onyeziri and Fuqua, 2021). All other data that support the findings of this study are available from the corresponding author upon reasonable request.

\section{References}

Anderson-Furgeson, J.C., Zupan, J.R., Grangeon, R., and Zambryski, P.C. (2016) Loss of PodJ in Agrobacterium tumefaciens leads to ectopic polar growth, branching, and reduced cell division. J Bacteriol 198: 1883-1891.

Baker, P., Hill, P.J., Snarr, B.D., Alnabelseya, N., Pestrak, M.J., Lee, M.J., Jennings, L.K., Tam, J., Melnyk, R.A., Parsek, M.R., Sheppard, D.C., Wozniak, D.J., and Howell, P.L. (2016) Exopolysaccharide biosynthetic glycoside hydrolases can be utilized to disrupt and prevent Pseudomonas aeruginosa biofilms. Science advances 2: e1501632.

Berne, C., Ellison, C.K., Ducret, A., and Brun, Y.V. (2018) Bacterial adhesion at the single-cell level. Nat Rev Microbiol 16: 616-627.

Braun, A.C., and Elrod, R.P. (1946) Stages in the life history of Phytomonas tumefaciens. J Bacteriol. 52: 695-702.

Breton, C., Snajdrova, L., Jeanneau, C., Koca, J., and Imberty, A. (2006) Structures and mechanisms of glycosyltransferases. Glycobiology 16: 29R-37R.

Brown, P.J., de Pedro, M.A., Kysela, D.T., Van der Henst, C., Kim, J., De Bolle, X., Fuqua, C., and Brun, Y.V. (2012) Polar growth in the Alphaproteobacterial order Rhizobiales. Proc Natl Acad Sci U S A 109: 1697-1701.

Camacho, C., Coulouris, G., Avagyan, V., Ma, N., Papadopoulos, J., Bealer, K., and Madden, T.L. (2009) BLAST+: architecture and applications. BMC Bioinformatics 10: 421.

Cangelosi, G.A., Hung, L., Puvanesarajah, V., Stacey, G., Ozga, D.A., Leigh, J.A., and Nester, E.W. (1987) Common loci for Agrobacterium tumefaciens and Rhizobium meliloti exopolysaccharide synthesis and their roles in plant interactions. $J$. Bacteriol. 169: 2086-2091.

Collins, R.F., Beis, K., Dong, C., Botting, C.H., McDonnell, C., Ford, R.C., Clarke, B.R., Whitfield, C., and Naismith, J.H. (2007) The 3D structure of a periplasm-spanning platform required for assembly of group 1 capsular polysaccharides in Escherichia coli. Proc Natl Acad Sci U S A 104: 2390-2395. 
Curtis, P.D., and Brun, Y.V. (2014) Identification of essential alphaproteobacterial genes reveals operational variability in conserved developmental and cell cycle systems. Mol Microbiol 93: 713-735.

Cuthbertson, L., Mainprize, I.L., Naismith, J.H., and Whitfield, C. (2009) Pivotal roles of the outer membrane polysaccharide export and polysaccharide copolymerase protein families in export of extracellular polysaccharides in gram-negative bacteria. Microbiol Mol Biol Rev 73: 155-177.

Davis, E.W., Weisberg, A.J., Tabima, J.F., Grunwald, N.J., and Chang, J.H. (2016) GallID: tools for genotyping gall-causing phytopathogenic bacteria. PeerJ 4: e2222.

De Castro, C., Molinaro, A., Lanzetta, R., Silipo, A., and Parrilli, M. (2008) Lipopolysaccharide structures from Agrobacterium and Rhizobiaceae species. Carbohydr Res 343: 1924-1933.

Feirer, N., Kim, D., Xu, J., Fernandez, N., Waters, C.M., and Fuqua, C. (2017) The Agrobacterium tumefaciens CheY-like protein ClaR regulates biofilm formation. Microbiology 163: 1680-1691.

Feirer, N., Xu, J., Allen, K.D., Koestler, B.J., Bruger, E.L., Waters, C.M., White, R.H., and Fuqua, C. (2015) A pterin-dependent signaling pathway regulates a dualfunction diguanylate cyclase-phosphodiesterase controlling surface attachment in Agrobacterium tumefaciens. mBio 6: e00156.

Fiebig, A., Herrou, J., Fumeaux, C., Radhakrishnan, S.K., Viollier, P.H., and Crosson, S. (2014) A cell cycle and nutritional checkpoint controlling bacterial surface adhesion. PLoS Genet 10: e1004101.

Flemming, H.C., Wingender, J., Szewzyk, U., Steinberg, P., Rice, S.A., and Kjelleberg, S. (2016) Biofilms: an emergent form of bacterial life. Nat Rev Microbiol 14: 563575.

Fritts, R.K., LaSarre, B., Stoner, A.M., Posto, A.L., and McKinlay, J.B. (2017) A Rhizobiales-specific unipolar polysaccharide adhesin contributes to Rhodopseudomonas palustris biofilm formation across diverse photoheterotrophic conditions. Appl Environ Microbiol 83.

Fuqua, C., (2008) Agrobacterium-host attachment and biofilm formation. In: Agrobacterium: From Biology to Biotechnology. T. Tzfira \& V. Citovsky (eds). New York, NY: Springer Science + Business Media LLC, pp. 243-277.

Gelvin, S.B. (2003) Agrobacterium-mediated plant transformation: the biology behind the "gene-jockeying" tool. Microbiol. Mol. Biol. Rev. 67: 16-37.

Gilchrist, C.L.M., and Chooi, Y.H. (2021) Clinker \& clustermap.js: Automatic generation of gene cluster comparison figures. Bioinformatics.

Ginsberg, C., Zhang, Y.H., Yuan, Y., and Walker, S. (2006) In vitro reconstitution of two essential steps in wall teichoic acid biosynthesis. ACS Chem Biol 1: 25-28.

Goodner, B., Hinkle, G., Gattung, S., Miller, N., Blanchard, M., Qurollo, B., Goldman, B.S., Cao, Y., Askenazi, M., Halling, C., Mullin, L., Houmiel, K., Gordon, J., Vaudin, M., lartchouk, O., Epp, A., Liu, F., Wollam, C., Allinger, M., Doughty, D., Scott, C., Lappas, C., Markelz, B., Flanagan, C., Crowell, C., Gurson, J., Lomo, C., Sear, C., Strub, G., Cielo, C., and Slater, S. (2001) Genome sequence of the plant pathogen and biotechnology agent Agrobacterium tumefaciens C58. Science 294: 2323-2328. 
Hardy, G.G., Allen, R.C., Toh, E., Long, M., Brown, P.J., Cole-Tobian, J.L., and Brun, Y.V. (2010) A localized multimeric anchor attaches the Caulobacter holdfast to the cell pole. Mol Microbiol 76: 409-427.

Heckel, B.C., Tomlinson, A.D., Morton, E.R., Choi, J.H., and Fuqua, C. (2014) Agrobacterium tumefaciens exoR controls acid response genes and impacts exopolysaccharide synthesis, horizontal gene transfer, and virulence gene expression. J Bacteriol 196: 3221-3233.

Hernando-Perez, M., Setayeshgar, S., Hou, Y., Temam, R., Brun, Y.V., Dragnea, B., and Berne, C. (2018) Layered structure and complex mechanochemistry underlie strength and versatility in a bacterial adhesive. $m B$ Bio 9 .

Hershey, D.M., Porfirio, S., Black, I., Jaehrig, B., Heiss, C., Azadi, P., Fiebig, A., and Crosson, S. (2019) Composition of the holdfast polysaccharide from Caulobacter crescentus. J Bacteriol 201.

Hinz, A.J., Larson, D.E., Smith, C.S., and Brun, Y.V. (2003) The Caulobacter crescentus polar organelle development protein PodJ is differentially localized and is required for polar targeting of the PleC development regulator. $\mathrm{Mol}$ Microbiol. 47: 929-941.

Holden, H.M., Rayment, I., and Thoden, J.B. (2003) Structure and function of enzymes of the Leloir pathway for galactose metabolism. J Biol Chem 278: 43885-43888.

Hong, Y., Liu, M.A., and Reeves, P.R. (2018) Progress in our understanding of Wzx flippase for translocation of bacterial membrane lipid-linked oligosaccharide. $J$ Bacteriol 200.

Hong, Y., Morcilla, V.A., Liu, M.A., Russell, E.L.M., and Reeves, P.R. (2015) Three Wzy polymerases are specific for particular forms of an internal linkage in otherwise identical O units. Microbiology (Reading) 161: 1639-1647.

Javens, J., Wan, Z., Hardy, G.G., and Brun, Y.V. (2013) Bypassing the need for subcellular localization of a polysaccharide export-anchor complex by overexpressing its protein subunits. Molecular Microbiology 89: 350-371.

Kamoun, S., Cooley, M.B., Rogowsky, P.M., and Kado, C.I. (1989) Two chromosomal loci involved in production of exopolysaccharide in Agrobacterium tumefaciens. $J$ Bacteriol 171: 1755-1759.

Khan, S.R., Gaines, J., Roop, R.M., 2nd, and Farrand, S.K. (2008) Broad-host-range expression vectors with tightly regulated promoters and their use to examine the influence of TraR and TraM expression on Ti plasmid quorum sensing. Appl Environ Microbiol 74: 5053-5062.

Lassalle, F., Campillo, T., Vial, L., Baude, J., Costechareyre, D., Chapulliot, D., Shams, M., Abrouk, D., Lavire, C., Oger-Desfeux, C., Hommais, F., Gueguen, L., Daubin, V., Muller, D., and Nesme, X. (2011) Genomic species are ecological species as revealed by comparative genomics in Agrobacterium tumefaciens. Genome Biol Evol 3: 762-781.

Laus, M.C., Logman, T.J., Lamers, G.E., Van Brussel, A.A., Carlson, R.W., and Kijne, J.W. (2006) A novel polar surface polysaccharide from Rhizobium leguminosarum binds host plant lectin. Mol Microbiol. 59: 1704-1713.

Li, G., Brown, P.J., Tang, J.X., Xu, J., Quardokus, E.M., Fuqua, C., and Brun, Y.V. (2012) Surface contact stimulates the just-in-time deployment of bacterial adhesins. Mol. Microbiol. 83: 41-51. 
Li, Y.G., and Christie, P.J. (2018) The Agrobacterium VirB/VirD4 T4SS: mechanism and architecture defined through in vivo mutagenesis and chimeric systems. Curr Top Microbiol Immunol 418: 233-260.

Lombard, V., Golaconda Ramulu, H., Drula, E., Coutinho, P.M., and Henrissat, B. (2014) The carbohydrate-active enzymes database (CAZy) in 2013. Nucleic Acids Res 42: D490-495.

Mathews, S.L., Hannah, H., Samagaio, H., Martin, C., Rodriguez-Rassi, E., and Matthysse, A.G. (2019) Glycoside hydrolase genes are required for virulence of Agrobacterium tumefaciens on Bryophyllum daigremontiana and tomato. Appl Environ Microbiol 85.

Morton, E.R., and Fuqua, C. (2012a) Genetic manipulation of Agrobacterium. Curr Protoc Microbiol: Unit 3D 2.

Morton, E.R., and Fuqua, C. (2012b) Laboratory maintenance of Agrobacterium. Curr Protoc Microbiol Chapter 1: Unit3D 1.

Morton, E.R., and Fuqua, C. (2012c) Phenotypic analyses of Agrobacterium. Curr Protoc Microbiol Chapter 3: Unit 3D 3.

Nguyen, L.T., Schmidt, H.A., von Haeseler, A., and Minh, B.Q. (2015) IQ-TREE: a fast and effective stochastic algorithm for estimating maximum-likelihood phylogenies. Mol Biol Evol 32: 268-274.

Oglesby, L.L., Jain, S., and Ohman, D.E. (2008) Membrane topology and roles of Pseudomonas aeruginosa Alg8 and Alg44 in alginate polymerization. Microbiology (Reading) 154: 1605-1615.

[dataset] Onyeziri, M.C. and Fuqua, C. Gene Expression Omnibus (GE), GEO identifier pending. All other data that support the findings of this study are available from the corresponding author upon reasonable request.

Poindexter, J.S. (1981) The caulobacters: ubiquitous unusual bacteria. Microbiol. Rev. 45: 123-179.

Reuber, T.L., and Walker, G.C. (1993) The acetyl substituent of succinoglycan is not necessary for alfalfa nodule invasion by Rhizobium meliloti Rm1021. J Bacteriol 175: 3653-3655.

Romling, U., and Galperin, M.Y. (2015) Bacterial cellulose biosynthesis: diversity of operons, subunits, products, and functions. Trends Microbiol 23: 545-557.

Ruan, X., Monjaras Feria, J., Hamad, M., and Valvano, M.A. (2018) Escherichia coli and Pseudomonas aeruginosa lipopolysaccharide O-antigen ligases share similar membrane topology and biochemical properties. Mol Microbiol 110: 95-113.

Schindelin, J., Arganda-Carreras, I., Frise, E., Kaynig, V., Longair, M., Pietzsch, T., Preibisch, S., Rueden, C., Saalfeld, S., Schmid, B., Tinevez, J.Y., White, D.J., Hartenstein, V., Eliceiri, K., Tomancak, P., and Cardona, A. (2012) Fiji: an opensource platform for biological-image analysis. Nat Methods 9: 676-682.

Slater, S.C., Goldman, B.S., Goodner, B., Setubal, J.C., Farrand, S.K., Nester, E.W., Burr, T.J., Banta, L., Dickerman, A.W., Paulsen, I., Otten, L., Suen, G., Welch, R., Almeida, N.F., Arnold, F., Burton, O.T., Du, Z., Ewing, A., Godsy, E., Heisel, S., Houmiel, K.L., Jhaveri, J., Lu, J., Miller, N.M., Norton, S., Chen, Q., Phoolcharoen, W., Ohlin, V., Ondrusek, D., Pride, N., Stricklin, S.L., Sun, J., Wheeler, C., Wilson, L., Zhu, H., and Wood, D.W. (2009) Genome sequences of 
three agrobacterium biovars help elucidate the evolution of multichromosome genomes in bacteria. J Bacteriol 191: 2501-2511.

Tempé, J., Petit, A., Holsters, M., Van Montagu, M., and Schell, J. (1977)

Thermosensitive step associated with transfer of the Ti plasmid during conjugation: possible relation to transformation in crown gall. Proc. Natl. Acad. Sci. USA 74: 2848-2849.

Thompson, M.A., Onyeziri, M.C., and Fuqua, C. (2018) Function and regulation of Agrobacterium tumefaciens cell surface structures that promote attachment. Curr Top Microbiol Immunol 418: 143-184.

Toh, E., Kurtz, H.D., Jr., and Brun, Y.V. (2008) Characterization of the Caulobacter crescentus holdfast polysaccharide biosynthesis pathway reveals significant redundancy in the initiating glycosyltransferase and polymerase steps. $J$ Bacteriol. 190: 7219-7231.

Tomlinson, A.D., and Fuqua, C. (2009) Mechanisms and regulation of polar surface attachment in Agrobacterium tumefaciens. Curr Opin Microbiol 12: 708-714.

Vetting, M.W., LP, S.d.C., Yu, M., Hegde, S.S., Magnet, S., Roderick, S.L., and Blanchard, J.S. (2005) Structure and functions of the GNAT superfamily of acetyltransferases. Arch Biochem Biophys 433: 212-226.

Vuong, C., Kocianova, S., Voyich, J.M., Yao, Y., Fischer, E.R., DeLeo, F.R., and Otto, M. (2004) A crucial role for exopolysaccharide modification in bacterial biofilm formation, immune evasion, and virulence. J Biol Chem 279: 54881-54886.

Wan, Z., Brown, P.J., Elliott, E.N., and Brun, Y.V. (2013) The adhesive and cohesive properties of a bacterial polysaccharide adhesin are modulated by a deacetylase. Mol Microbiol 88: 486-500.

Weisberg, A.J., Davis, E.W., 2nd, Tabima, J., Belcher, M.S., Miller, M., Kuo, C.H., Loper, J.E., Grunwald, N.J., Putnam, M.L., and Chang, J.H. (2020) Unexpected conservation and global transmission of agrobacterial virulence plasmids. Science 368.

Whitfield, C., Wear, S.S., and Sande, C. (2020) Assembly of bacterial capsular polysaccharides and exopolysaccharides. Annu Rev Microbiol 74: 521-543.

Williams, A., Wilkinson, A., Krehenbrink, M., Russo, D.M., Zorreguieta, A., and Downie, J.A. (2008) Glucomannan-mediated attachment of Rhizobium leguminosarum to pea root hairs is required for competitive nodule infection. J Bacteriol. 190: 47064715.

Wood, D.W., Setulab, J.C., Kaul, R., Monks, D.E., Kitajima, J.P., Okura, V.K., Zhou, Y., Chen, L., Wood, G.E., Almeida, N.F.J., Woo, L., Chen, Y., Paulsen, I.T., Eisen, J.A., Karp, P.D., Dovee, D.S., Chapman, P., Clendenning, J., Deatherage, G., Gillet, W., Grant, C., Kutyavin, T., Levy, R., Li., M.-J., McClellund, E., Palmieri, A., Raymond, C., Rouse, G., Saenphimmachak, C., Wu, Z., Romero, P., Gordon, D., Zhang, S., Yoo, H., Tao, Y., Biddle, P., Jung, M., Krespan, W., Perry, M., Gordon-Kamm, B., Liao, L., Kim, S., Hendrick, C., Zhao, Z.-Y., Dolan, M., Chumley, F., Tingey, S.V., Tomb, J.-F., Gordon, M., Olson, M.V., and Nester, E.W. (2001) The genome of the natural genetic engineer Agrobacterium tumefaciens C58. Science 294: 2317-2323. 
Xu, J., Kim, J., Danhorn, T., Merritt, P.M., and Fuqua, C. (2012) Phosphorus limitation increases attachment in Agrobacterium tumefaciens and reveals a conditional functional redundancy in adhesin biosynthesis. Res Microbiol 163: 674-684.

Xu, J., Kim, J., Koestler, B.J., Choi, J.H., Waters, C.M., and Fuqua, C. (2013) Genetic analysis of Agrobacterium tumefaciens unipolar polysaccharide production reveals complex integrated control of the motile-to-sessile switch. Mol Microbiol 89: 929-948.

Yildiz, F., Fong, J., Sadovskaya, I., Grard, T., and Vinogradov, E. (2014) Structural characterization of the extracellular polysaccharide from Vibrio cholerae O1 ElTor. PLoS One 9: e86751. visualization and annotation of phylogenetic trees with their covariates and other associated data. Meth. Ecol. Evol. 8: 28-36.

Zhang, H.B., Wang, C., and Zhang, L.H. (2004) The quormone degradation system of Agrobacterium tumefaciens is regulated by starvation signal and stress alarmone (p)ppGpp. Mol Microbiol 52: 1389-1401.

Zhang, Y.M., Tian, C.F., Sui, X.H., Chen, W.F., and Chen, W.X. (2012) Robust markers reflecting phylogeny and taxonomy of rhizobia. PLoS One 7: e44936. 


\section{Figure 1. UPP-mediated polar attachment in A. tumefaciens.}

1315 Figure 1. A. tumefaciens UPP on abiotic surfaces and plant tissues. Fluorescence

1316 microscopy using wheat germ agglutinin lectin labeled with FTIC (fl-WGA) and

1317 Alexafluor 594 (af-WGA). (A-C) Attachment assays on $22 \times 22$ mm glass coverslips. A.

1318 tumefaciens C58 cells incubated for the indicated time in ATGN minimal medium with

1319 coverslips prior to lectin labeling with $10 \mu \mathrm{g} / \mathrm{ml}$ of either fl-WGA or af-WGA for 20 min.

1320 (A) fl-WGA labeling of a $12 \mathrm{hr}$ biofilm. Merged image from bright field and fluorescence

1321 microscopy. (B) af-WGA-labeling of a short-term attachment assay after 2 hrs

1322 incubation. Merged image from phase contrast and fluorescence. (C) af-WGA labeling

1323 of a single $A$. tumefaciens cell attached to glass expressing plasmid-borne $P_{\text {tac: }: \text { gfpmut3 }}$

1324 (pJZ383). Scanning Disk Laser Confocal fluorescence microscopy; Merged green and

1325 red channels, pseudo-colored yellow and magenta, respectively. (D) Binding of $A$.

1326 tumefaciens (pJZ383) to Arabidopsis thaliana WS $1 \mathrm{~cm}$ root cutting incubated for $3 \mathrm{hrs}$

1327 in ATGN minimal medium. Merged green and red channels pseudo-colored yellow and

1328 magenta, respectively plus bright field. Microscopes: Nikon E800 fluorescence

1329 microscope and Photometrics Cascade cooled CCD camera; Spinning Disk Nikon

1330 TE2000U microscope Yokagawa CSU10 confocal scanner unit. Fluorescence settings:

1331 fl-WGA and GFP, excitation, 460-500 nm, emission 510-560 nm; af-WGA, excitation

$1332 \quad 510-560 \mathrm{~nm}$, emission $>610 \mathrm{~nm}$. 
1334 Figure 2. UPP biosynthesis gene clusters and Congo red colony phenotypes in $A$.

tumefaciens. Gene clusters important for UPP biosynthesis that were identified via

1336 transposon screens for mutants with decreased Congo red (DCR) phenotypes.

1337 Stemmed circles represent independent, sequenced transposon insertion sites. Letters

1338 A-G designate specific genetic loci. The single unfilled marker upstream of uppE

1339 represents a transposon mutant isolated based on a biofilm deficiency (Xu et al., 2012).

1340 Numbers with $\mathrm{X}$ indicate 14 or more independent transposon insertions. Boxed gene

1341 names and designations indicate genes for which in-frame-deletions in wild type do not

1342 lead to attachment deficiencies. Predicted functions based in sequence similarity are

1343 described in the key below the gene map and are color-coded. Inset boxes on the upper

1344 right provide CR phenotypes of $A$. tumefaciens strains lacking all the known

1345 dispensable exopolysaccharides except UPP (CDGS-), the same strain elevated for

1346 cdGMP via a $d c p A$ deletion and thus exhibiting an elevated Congo red (ECR)

1347 phenotype (middle), and the same strain with a Mariner transposon insertion in uppE

1348 conferring a DCR phenotype.

1350 Figure 3. Biofilm phenotypes of uppA-F mutants. Ratio of acetic acid-solubilized CV

1351 absorbance ( $\mathrm{A}_{600}$ ) from $48 \mathrm{~h}$ biofilm assays normalized to the OD 600 turbidity measured

1352 from the planktonic phase of the same culture. Ratio for wild type set to $100 \%$ and

1353 mutant derivatives expressed as percent wild type. Blue bars are the strains harboring

1354 the pSRK-Gm vector, red bars are expressing pSRK-Gm derivatives with the

1355 corresponding gene, and the single green bar is the $\Delta u p p C$ strain expressing a pSR- 
1356 Gm derivative with uppC and uppD. All assays were performed with $500 \mu \mathrm{M}$ IPTG.

1357 Bars represent the mean of triplicate assays and error bars are standard deviation.

1359 Figure 4. af-WGA labeling of UPP in uppA-F mutants. Short term binding assays of

1360 A. tumefaciens C58 derivatives on glass coverslips stained with af-WGA. Phase

1361 images, fluorescence images (510-560 nm excitation, emission >610 nm), and merged

1362 images. Microscopy was performed as described in experimental procedures on a

1363 Nikon Eclipse Ti-E microscope with a Nikon E800 camera with the 60X oil immersion

1364 objective and NIS-Elements Software, and analyzed with Fiji (Schindelin et al., 2012).

1367 mutants. (A) Biofilm assays performed as in Fig. 3 for flippase deletion mutants and 1368 complementation strains. WT biofilm was set to $100 \%$. Plasmid-borne copies of genes 1369 were expressed from the $P_{\text {lac }}$ promoter in pSRK derivatives induced with $500 \mu \mathrm{M}$ IPTG.

1370 Bars represent the mean of triplicate assays and error bars are standard deviation. (B)

1371 Short term attachment assays as in Fig. 4, co-incubated with af-WGA (red) and fl-DBA 1372 (green). Only merged images shown. Microscopy as described in Fig. 4. af-WGA

1373 (excitation 510-560 nm, emission >610 nm); fl-DBA (excitation 460-500 nm, emission $1374 \quad 510-560 \mathrm{~nm})$. 
1378 independent, sequenced transposon insertion sites and numbers with $\mathrm{X}$ indicate 14 or

1379 more independent transposon insertions. (B) ATGN CR colony phenotypes of the

1380 indicated deletion mutants in the $\triangle$ pruA CDGS- background. (C) Quantitative biofilm

1381 assay as performed in Fig. 3 with the ratio of $A_{600}$ of acetic acid-solubilized CV-stained

1382 coverslips to planktonic OD 600 normalized to percent wild type for the indicated in-frame

1383 deletion mutants in otherwise wild type C58 after $48 \mathrm{~h}$ incubation in ATGN. The

1384 indicated strains with solid black and light orange bars have the pSRK-Gm vector

1385 control, whereas the strains represented by dark orange bars harbor a $P_{\text {lac }}$ uppY

1386 plasmid and the strains with cross hatched bars harbor the $P_{l a c}-u p p W$ plasmid. Cultures

1387 grown in $400 \mu \mathrm{M}$ IPTG to induce $P_{\text {lac. }}$. Error bars are standard deviation of assays

1388 performed in triplicate.

Figure 7. Dual lectin binding of wild type UPP with WGA and DBA. Short term

1391 attachment assay on a glass coverslip co-incubated with lectins. (A) UPP stained with

1392 af-WGA showing red fluorescent polar foci. (B) UPP stained with fl-DBA showing green

1393 fluorescent polar foci. (C) UPP stained with both af-WGA and fl-DBA showing the

1394 sectored pattern of dual red and green fluorescence. Arrows indicate clearly labeled

1395 UPP. Insets - magnification of boxed area. (D) Image of two attached dual labeled cells

1396 at the focal plane of surface contact. Microscopy as in Fig. 5.

1398 Figure 8. Dual lectin binding in $\Delta u p p W$ and $\Delta u p p Y$ mutants shows reciprocal

1399 specificity. Short term attachment assay on a glass coverslip co-incubated with WT, $1400 \Delta u p p Y, \Delta u p p W$, and $\Delta u p p Y \Delta u p p W$ mutants co-incubated with af-WGA and fl-DBA 
1401 showing reciprocal fluorescence of the polymerase mutants. Microscopy as in Fig. 5,

1402 but only merged images are shown.

1403

1404 Figure 9. Transmission electron microscopy (TEM) of UPP from polymerase

1405 deletion mutants. TEM analysis of $A$. tumefaciens $\triangle p r u A$ CDGS- mutant derivatives on 1406 a JEOL JEM-1010 Transmission Electron Microscope at 80 kV. (A) TEM using WGA

1407 conjugated with gold beads (20 nm). (A) TEM using PNA conjugated with gold beads $1408(10 \mathrm{~nm})$.

1411 and His6-UppH ${ }^{* *}$ at $1 \mathrm{mM}$ were incubated for $1 \mathrm{~h}$ with $A$. tumefaciens $\Delta$ pruA CDGS-. (A)

1412 Cells were pre-attached to glass coverslips prior to incubation with UppH preparations, 1413 and subsequently labeled with af-WGA and fl-DBA. Microscopy performed as in Fig. 5, 1414 with only the merged phase contrast and fluorescence images shown. (B) TEM

1415 performed on cells following incubation with UppH preparations as in Fig. 9, but without 1416 the addition of gold-labeled lectins.

1418 Figure 11. Genes isolated in UPP pathway-specific screens. On the y-axis are 1419 number of independent transposon insertions that resulted in a scorable DCR 1420 phenotype for the $\triangle p r u A$ (CDGS-) polymerase deletion mutants ( $\triangle u p p Y$ and $\Delta u p p W$ ), 1421 and on the $\mathrm{x}$-axis are the genes identified with transposon insertions. Red bars indicate 1422 genes disrupted in the $\triangle u p p Y$ background and therefore predicted to be important for 1423 UPP $_{\text {GICN }}$ synthesis. Green bars indicate genes identified in the $\Delta$ uppW background and 
1424 thus predicted to be important in the synthesis of UPPGalN. Red and green bars together

1425 indicate genes identified in both mutant screening backgrounds.

1427 Figure 12. Model of UPP biosynthesis pathway in A. tumefaciens. Dual Wzx/Wzy

1428 polysaccharide biosynthesis pathway showing proteins that exhibit specificity for

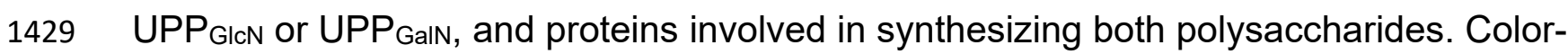

1430 coding is consistent with the legend in Fig. 2. IM - inner membrane; PG- Peptidoglycan;

1431 OM - outer membrane; GT - glycosyl transferase; Ac - acetylation. 
bioRxiv preprint doi: https://doi.org/10.1101/2021.04.22.440995; this version posted April 24, 2021. The copyright holder for this preprint (which was not certified by peer review) is the author/funder, who has granted bioRxiv a license to display the preprint in perpetuity. It is made available under aCC-BY-NC-ND 4.0 International license.

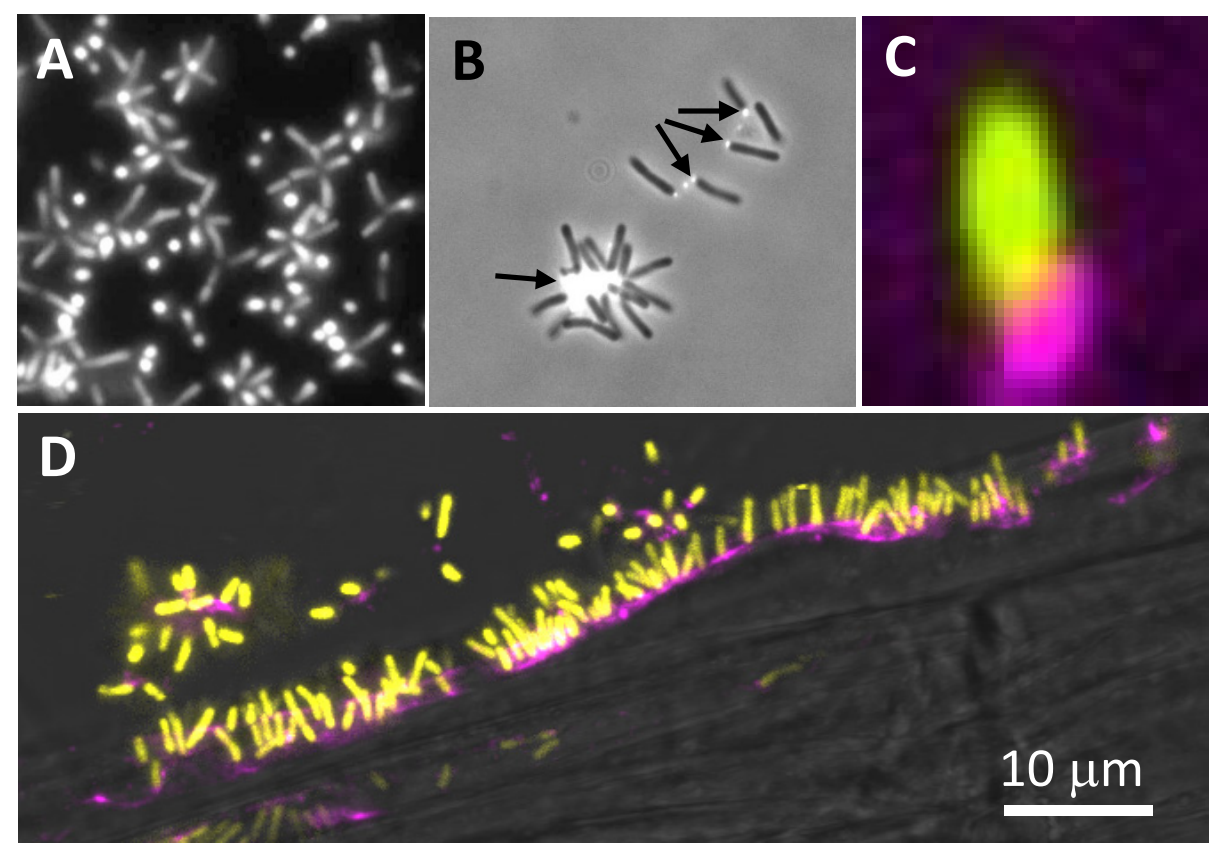

Figure 1 - Onyeziri et al. 


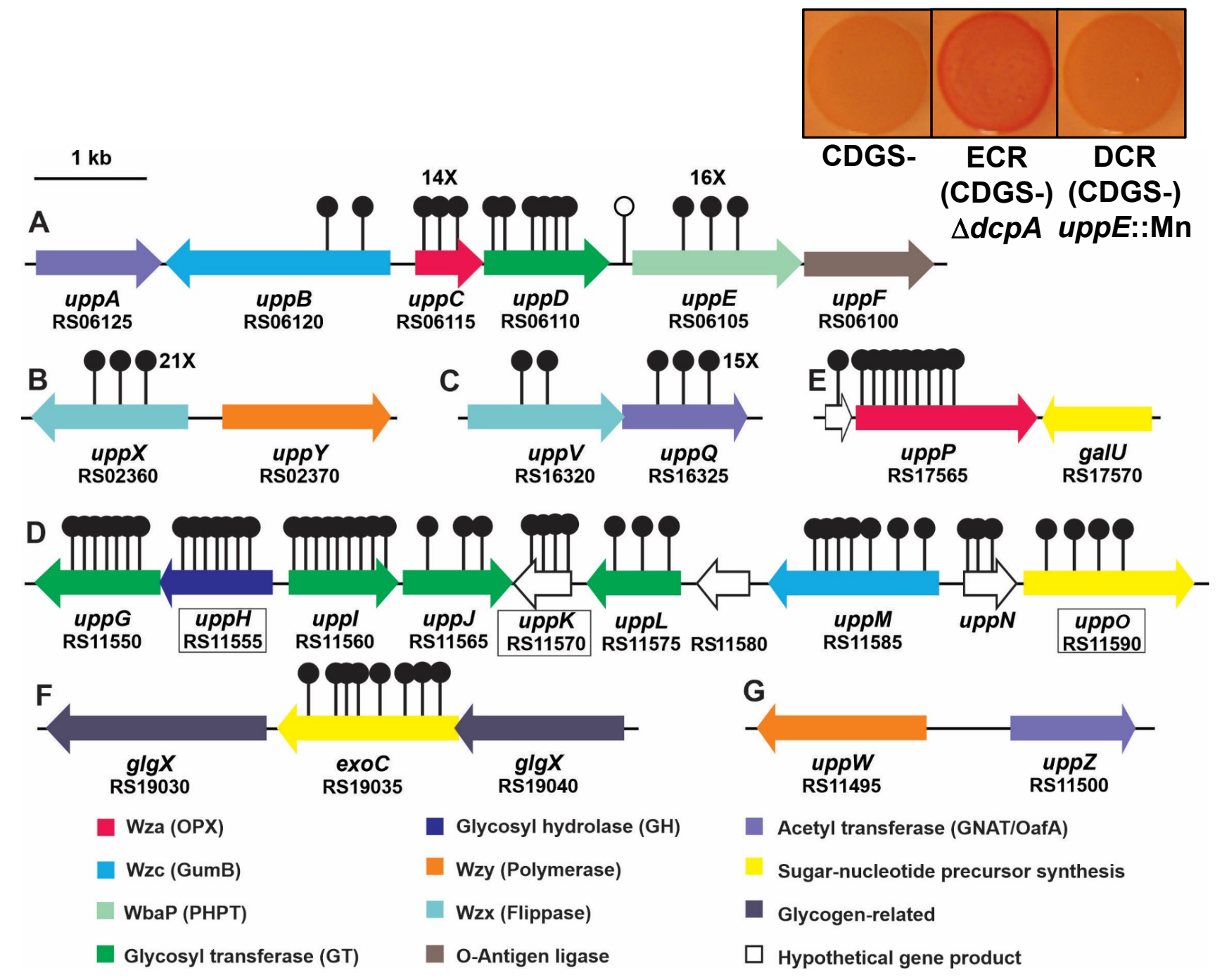

Figure 2 - Onyeziri et al. 


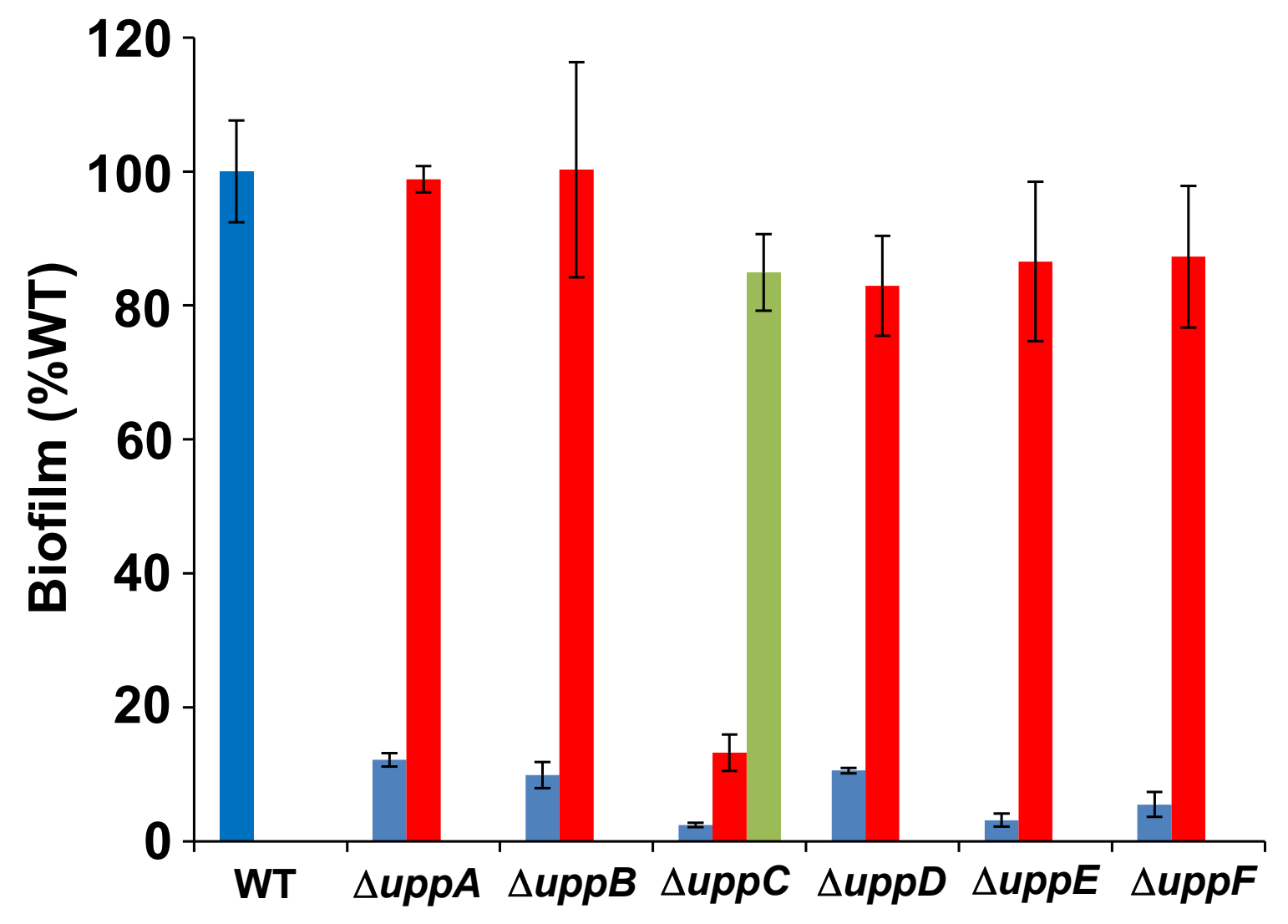

Figure 3 - Onyeziri et al. 
bioRxiv preprint doi: https://doi.org/10.1101/2021.04.22.440995; this version posted April 24, 2021. The copyright holder for this preprint (which was not certified by peer review) is the author/funder, who has granted bioRxiv a license to display the preprint in perpetuity. It is made available under aCC-BY-NC-ND 4.0 International license.

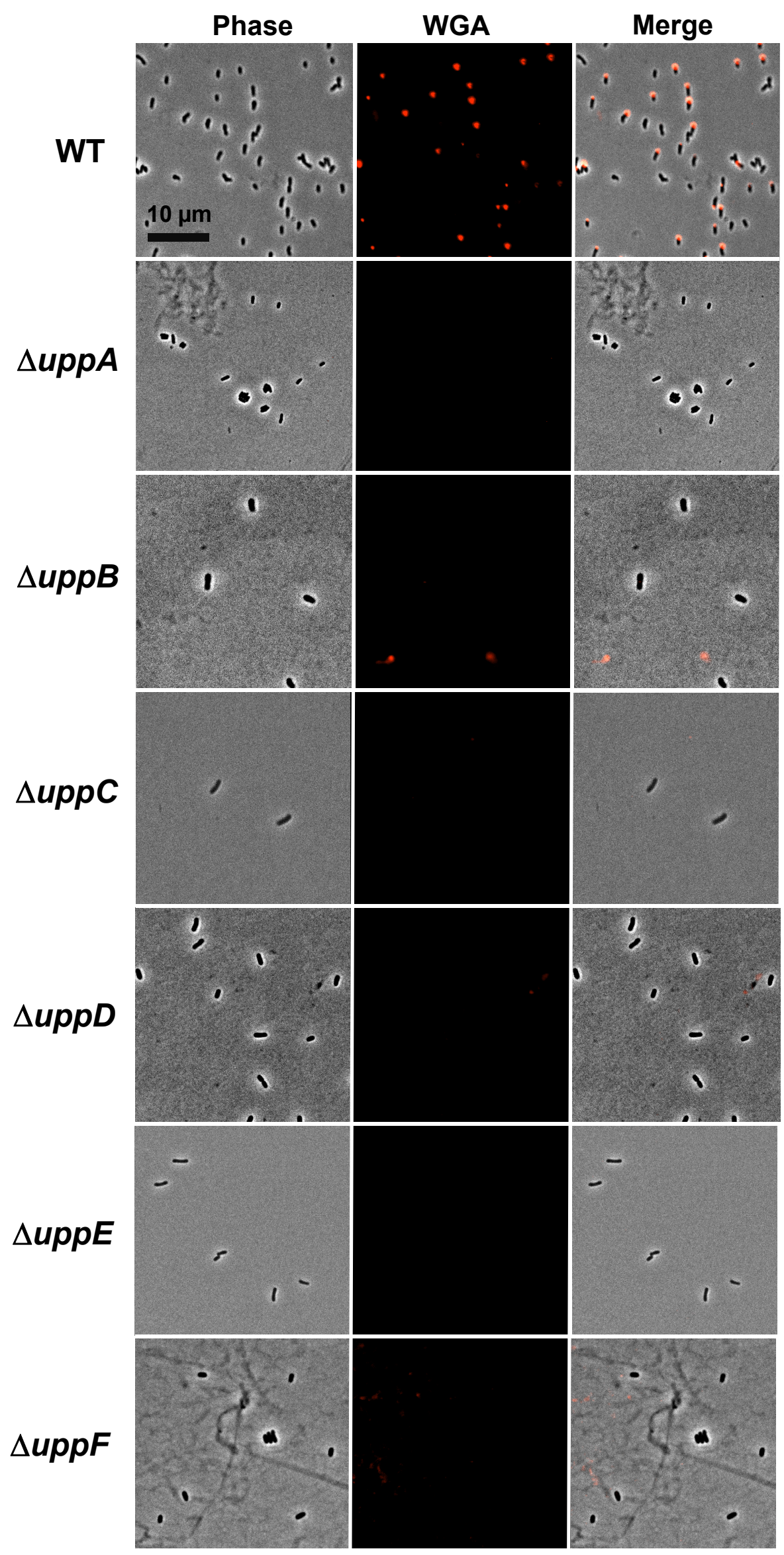

Figure 4 - Onyeziri et al. 


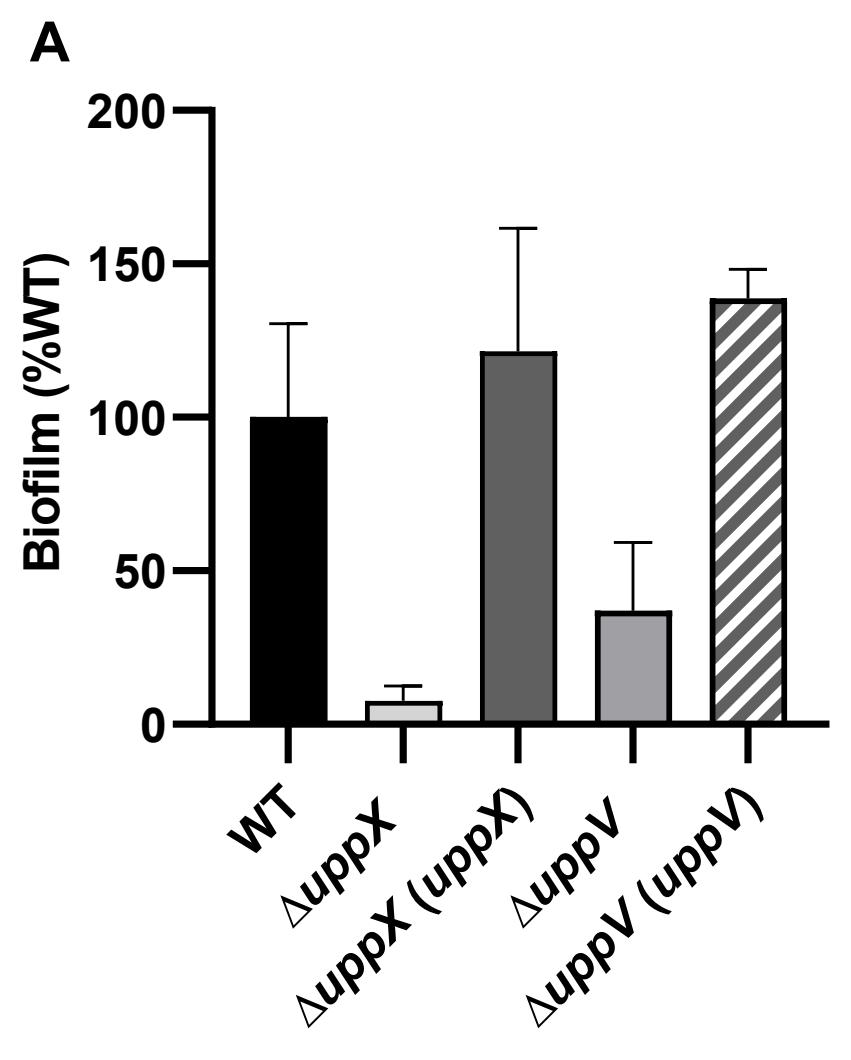

B

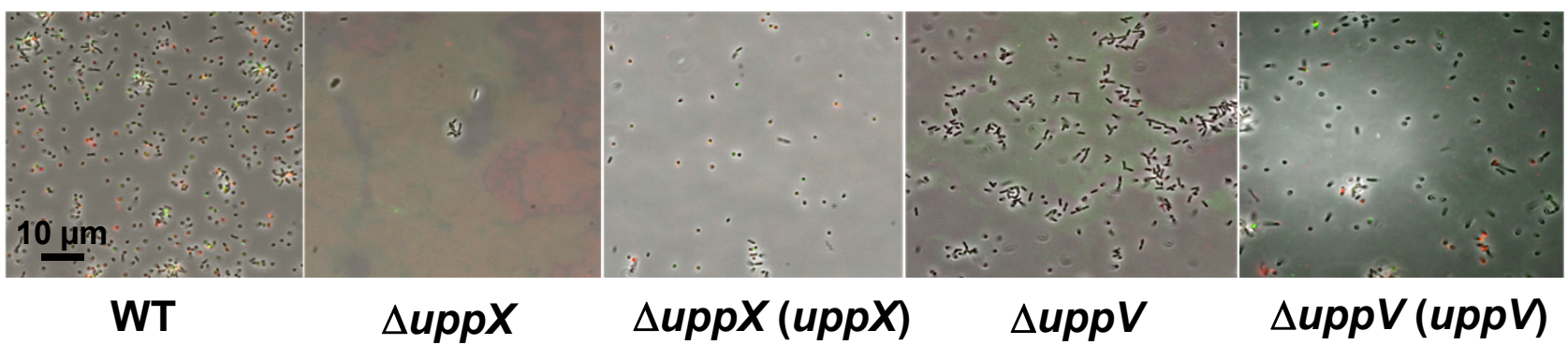




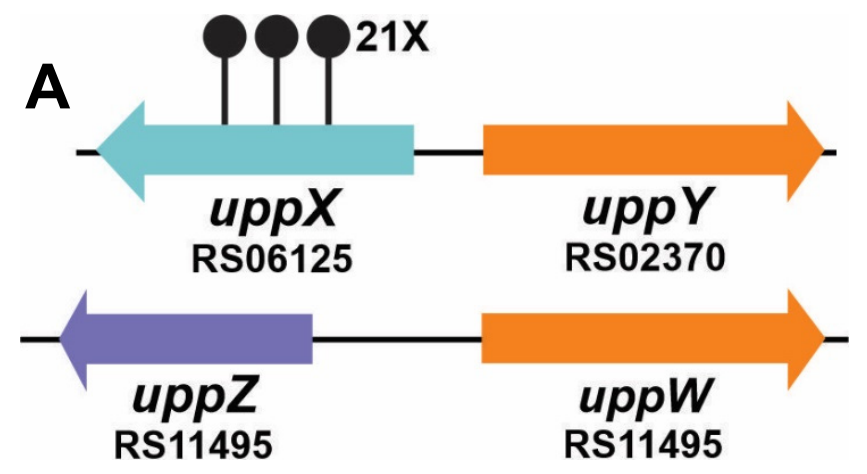

B
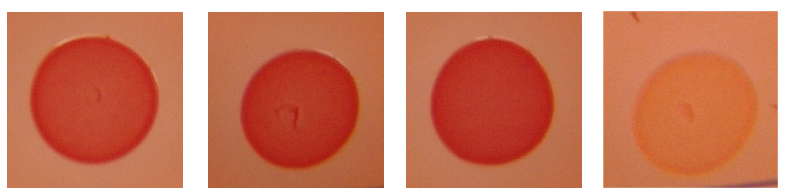

$\Delta p r u A$

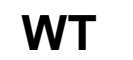

$\Delta u p p Y \quad \Delta u p p W$

$\Delta u p p Y$

CDGS-

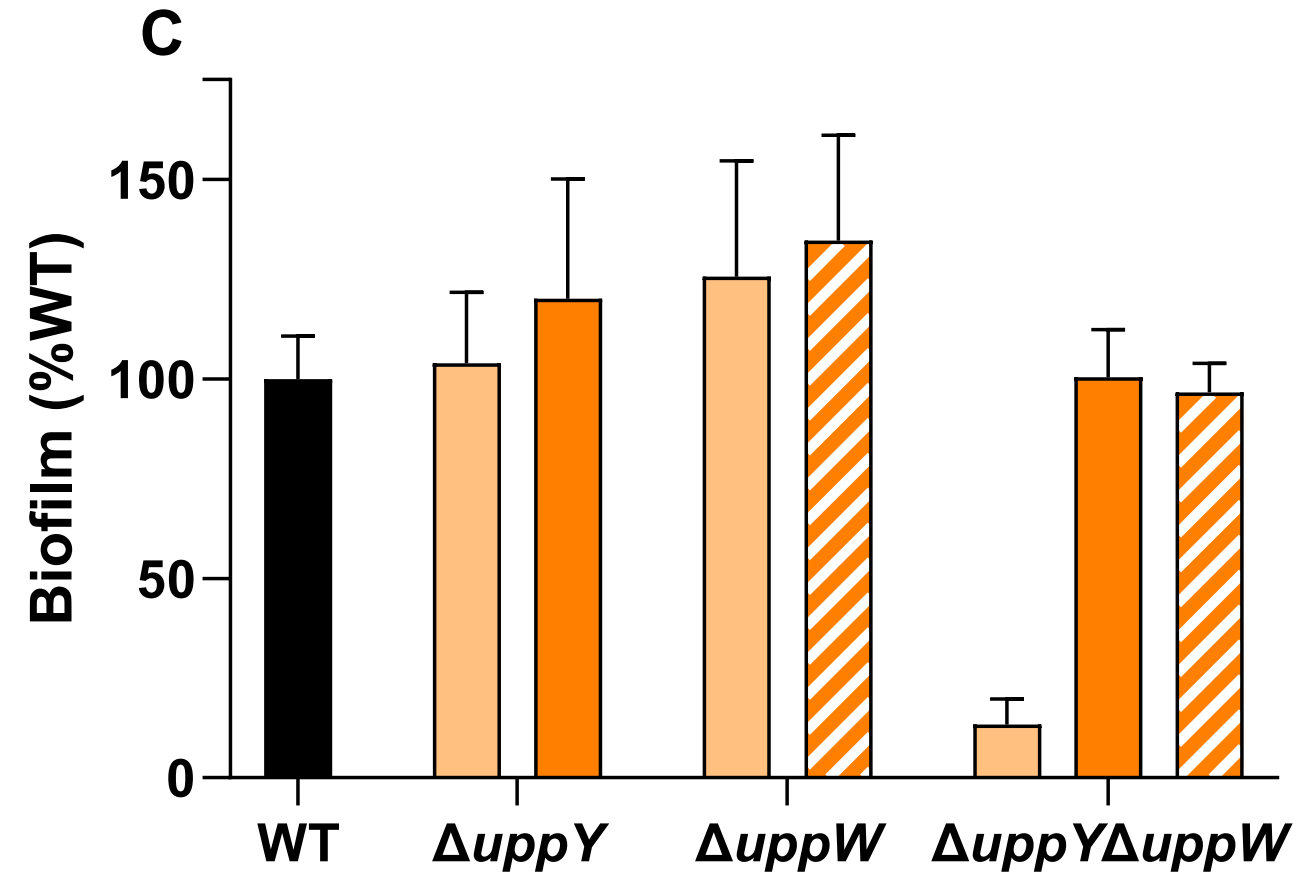

Figure 6 - Onyeziri et al. 
bioRxiv preprint doi: https://doi.org/10.1101/2021.04.22.440995; this version posted April 24, 2021. The copyright holder for this preprint (which was not certified by peer review) is the author/funder, who has granted bioRxiv a license to display the preprint in perpetuity. It is made available under aCC-BY-NC-ND 4.0 International license.

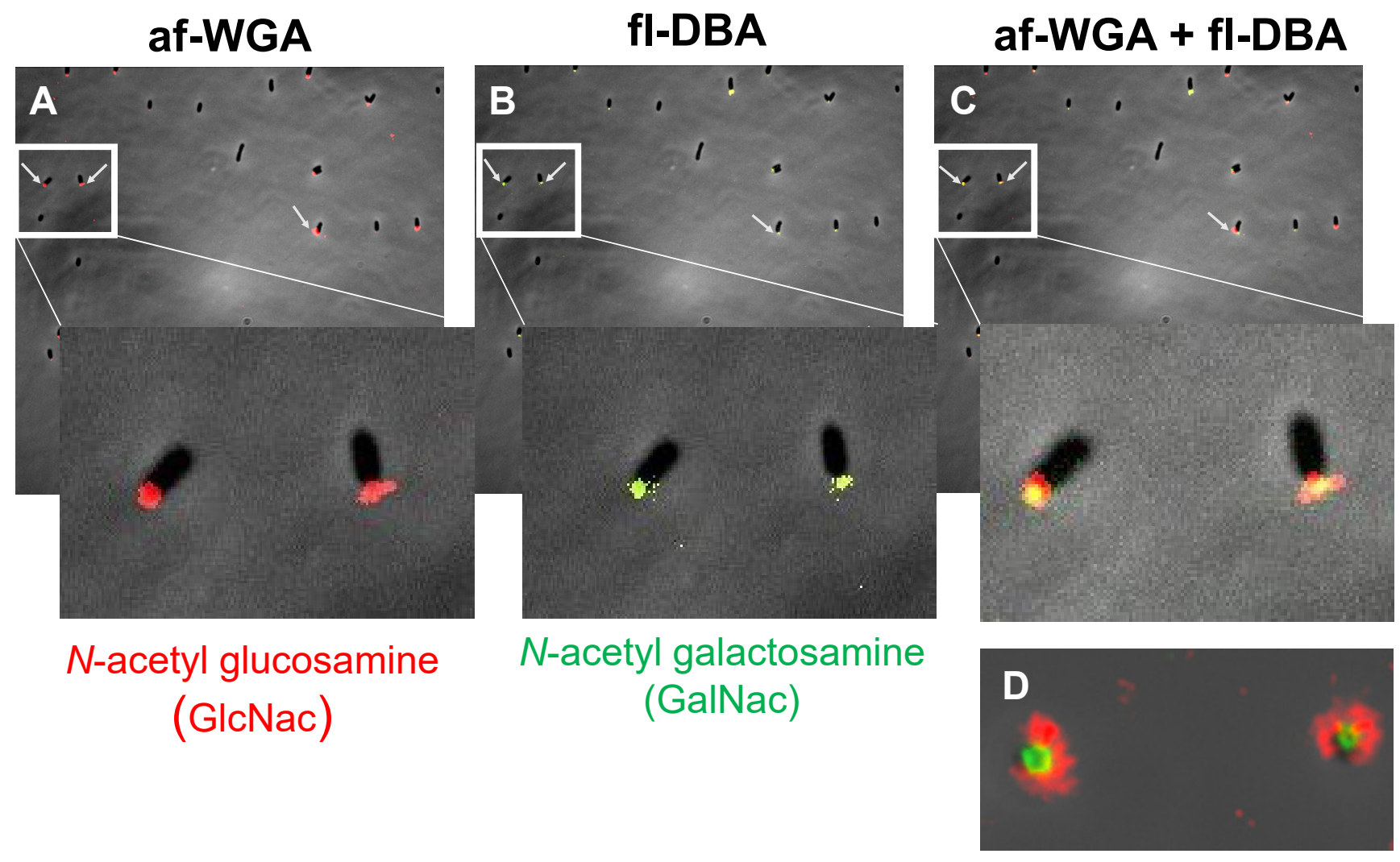

Figure 7 - Onyeziri et al. 
bioRxiv preprint doi: https://doi.org/10.1101/2021.04.22.440995; this version posted April 24, 2021. The copyright holder for this preprint (which was not certified by peer review) is the author/funder, who has granted bioRxiv a license to display the preprint in perpetuity. It is made available under aCC-BY-NC-ND 4.0 International license.

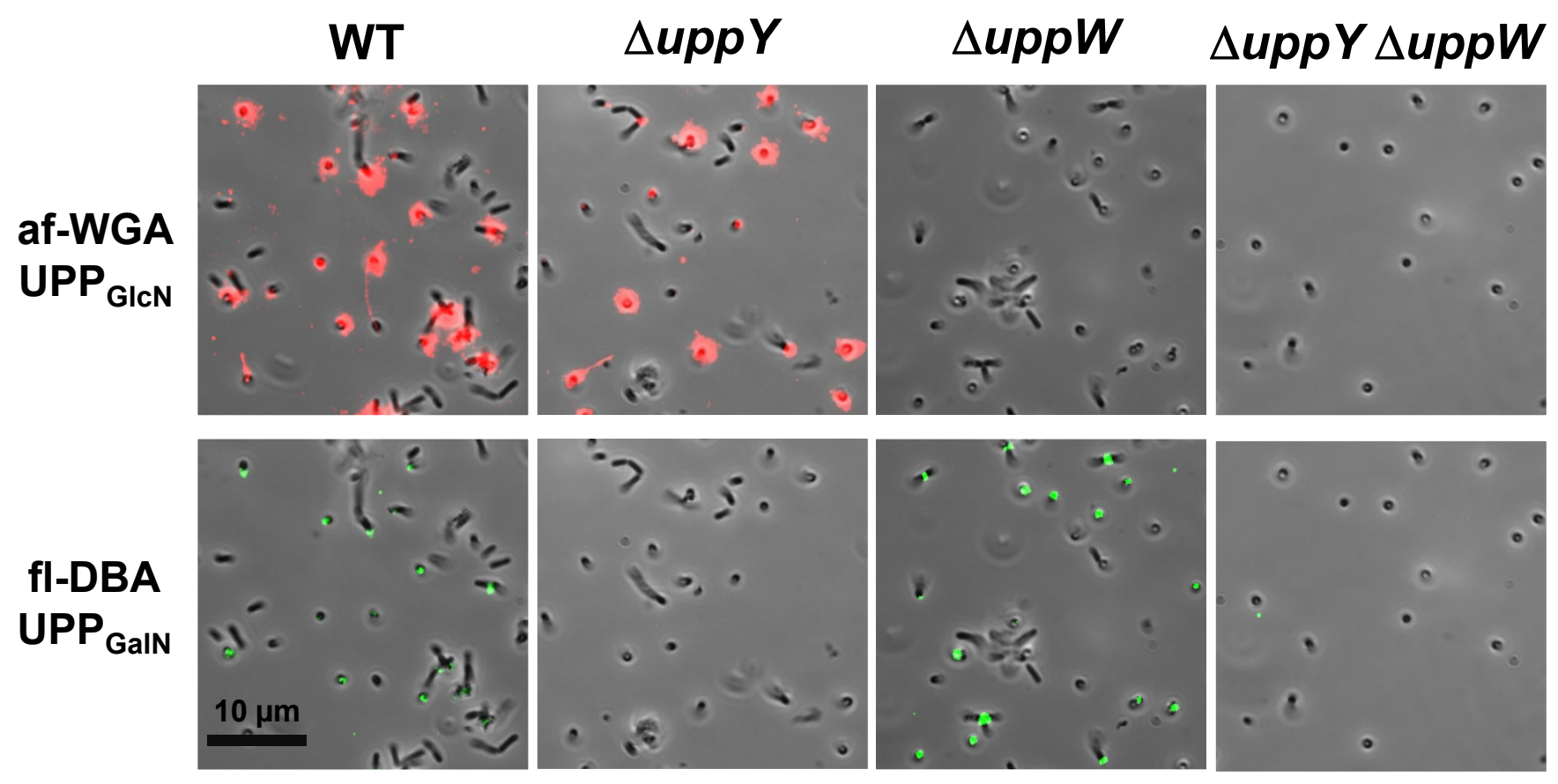

Figure 8 - Onyeziri et al. 
bioRxiv preprint doi: https://doi.org/10.1101/2021.04.22.440995; this version posted April 24, 2021. The copyright holder for this preprint (which was not certified by peer review) is the author/funder, who has granted bioRxiv a license to display the preprint in perpetuity. It is made available under aCC-BY-NC-ND 4.0 International license.

\section{$\triangle$ pruA CDGS-}

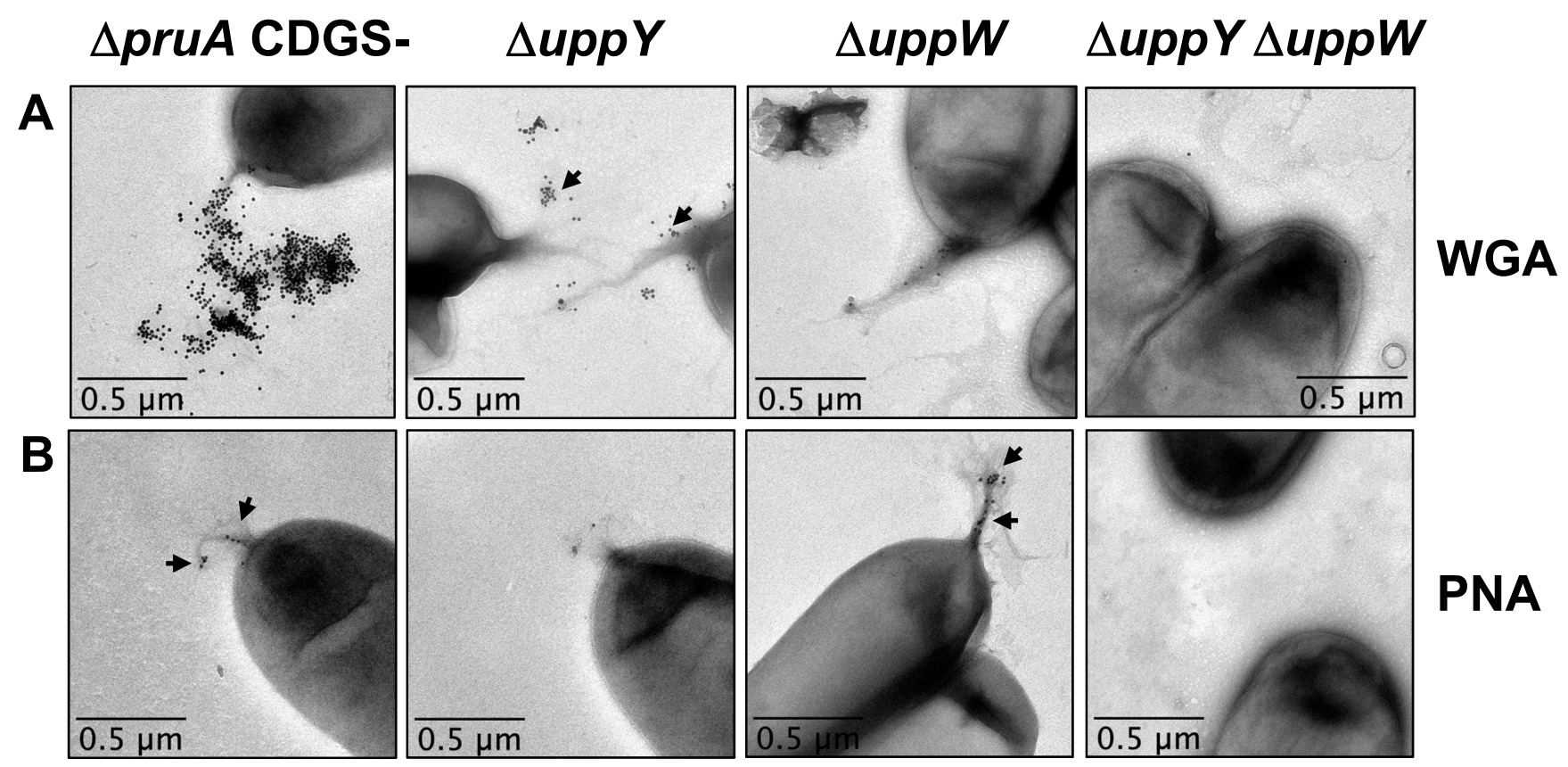

Figure 9 - Onyeziri et al. 
bioRxiv preprint doi: https://doi.org/10.1101/2021.04.22.440995; this version posted April 24, 2021. The copyright holder for this preprint (which

was not certified by peer review) is the author/funder, who has granted bioRxiv a license to display the preprint in perpetuity. It is made available under aCC-BY-NC-ND 4.0 International license.
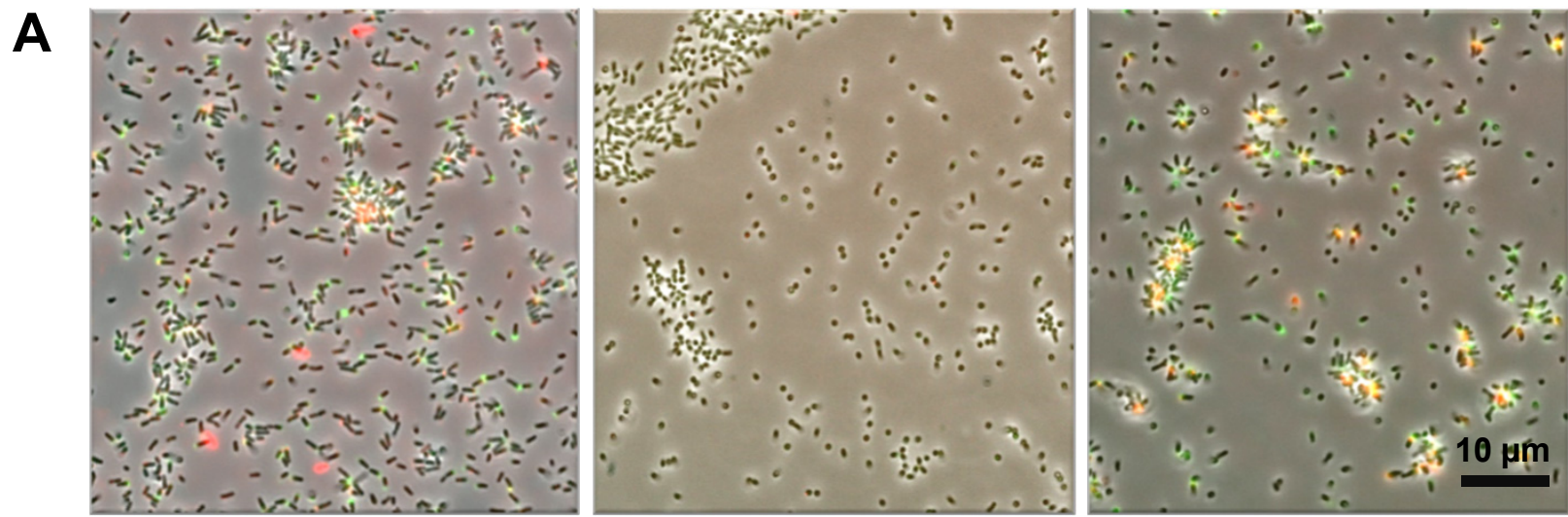

B

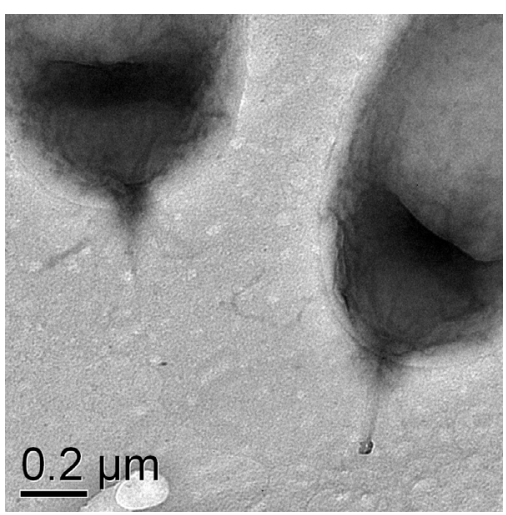

No addition

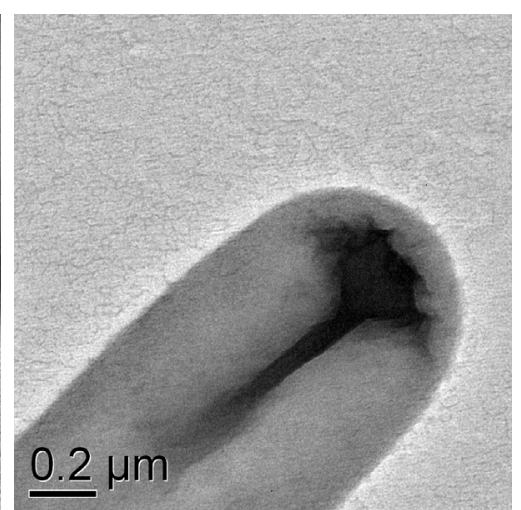

UppH (1 mM)

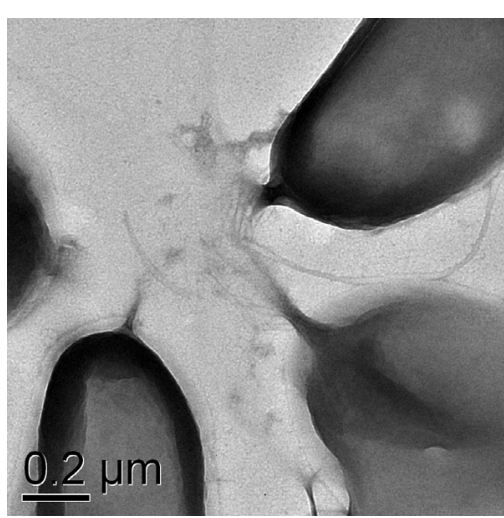

$\mathrm{UppH}^{* *}(1 \mathrm{mM})$

Figure 10 - Onyeziri et al. 


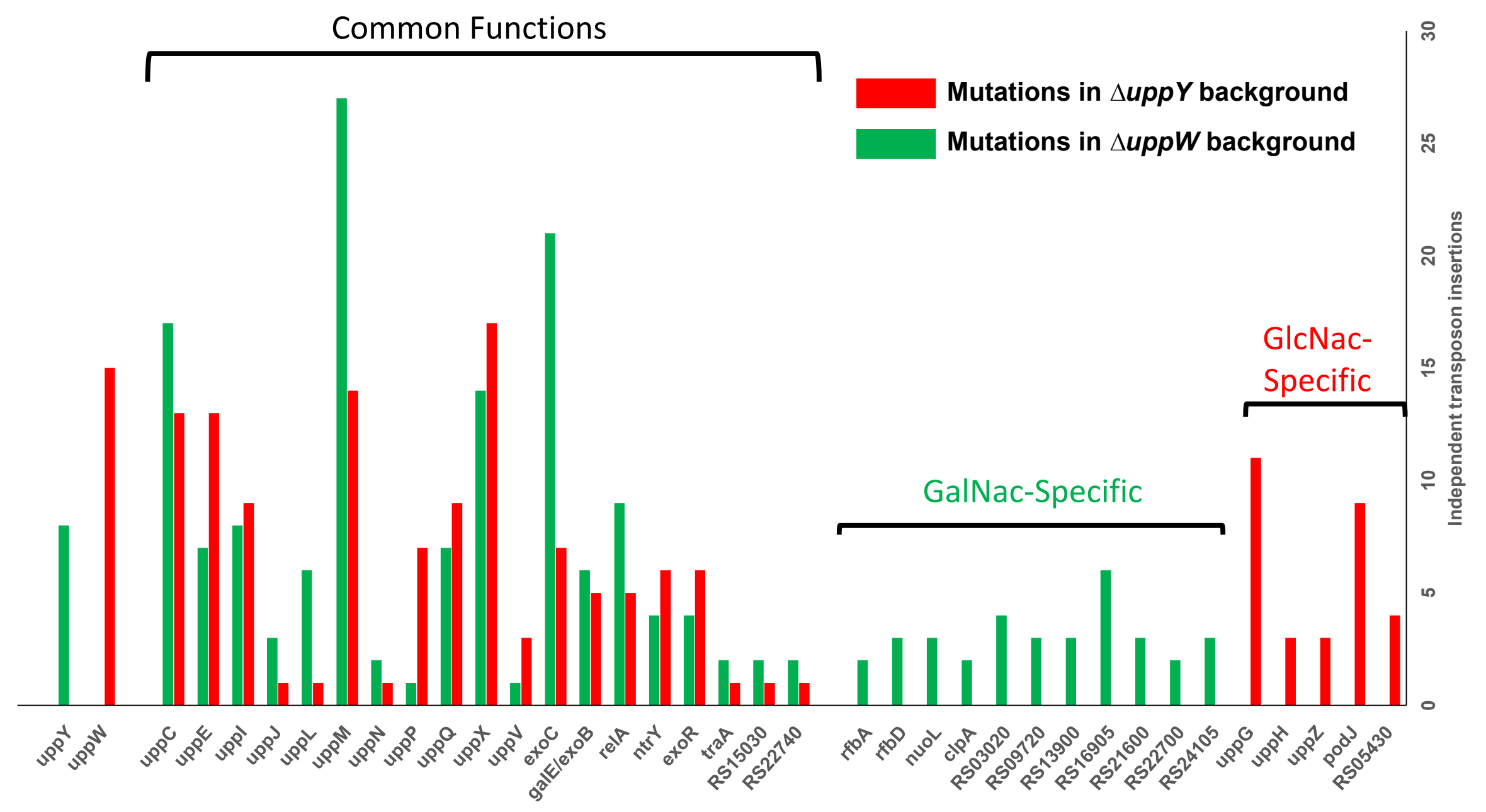

Figure 11 - Onyeziri et al. 


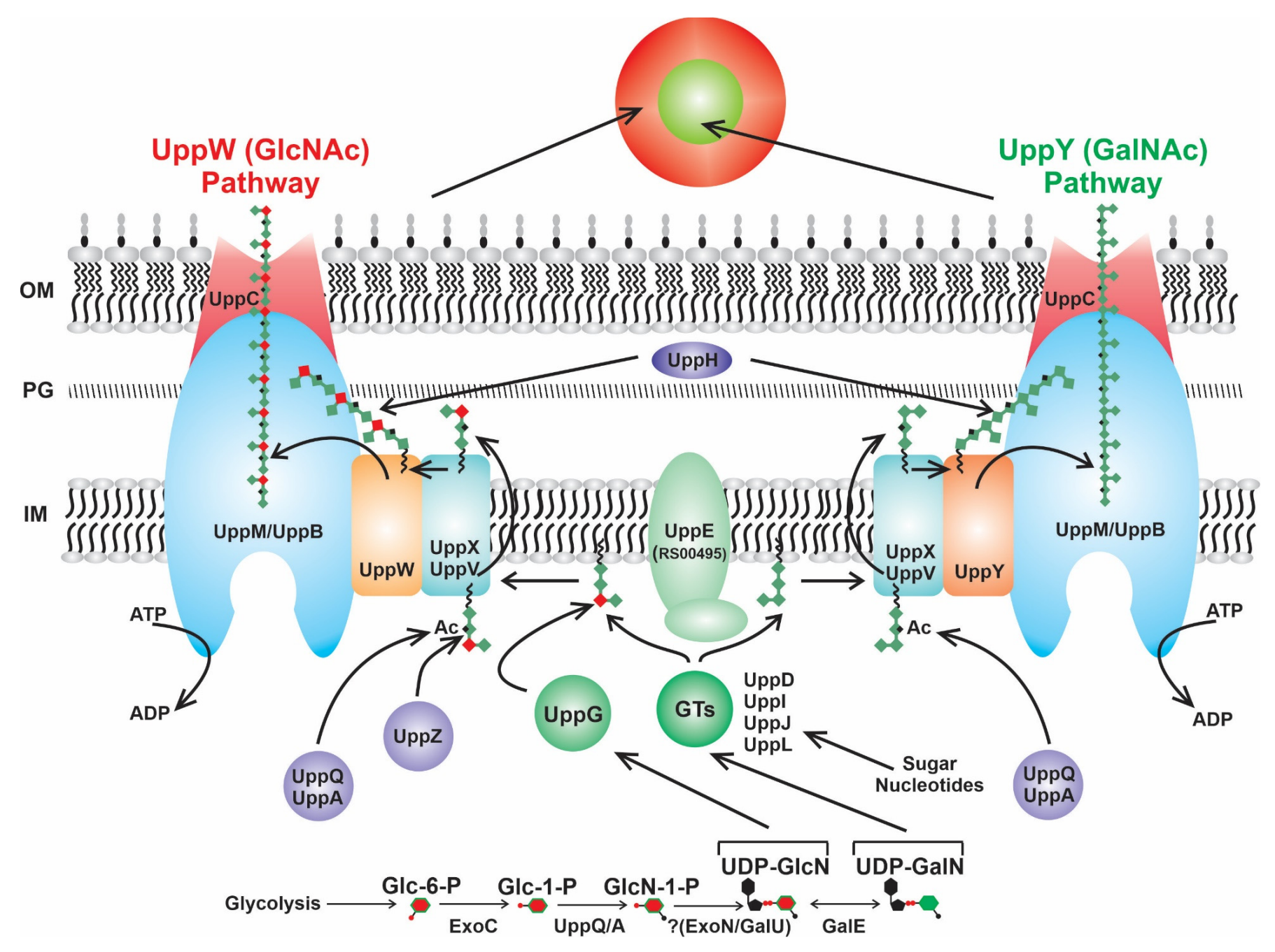

Figure 12 - Onyeziri et al. 